TI 2016-032/VI

Tinbergen Institute Discussion Paper

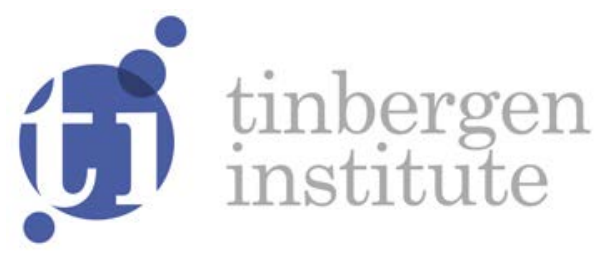

\title{
Redistributive Politics and the Tyranny of the Middle Class
}

Floris T. Zoutman'

Bas Jacobs ${ }^{2}$

Egbert L. W. Jongen 3

${ }^{7}$ NHH Norwegian School of Economics, Norway:

2 Erasmus School of Economics, Erasmus University Rotterdam, and Tinbergen Institute Rotterdam, the Netherlands;

${ }^{3}$ CPB Netherlands Bureau for Economic Policy Analysis, The Hague; and Leiden University, the Netherlands. 
Tinbergen Institute is the graduate school and research institute in economics of Erasmus University Rotterdam, the University of Amsterdam and VU University Amsterdam.

More TI discussion papers can be downloaded at http://www.tinbergen.nl

Tinbergen Institute has two locations:

Tinbergen Institute Amsterdam

Gustav Mahlerplein 117

1082 MS Amsterdam

The Netherlands

Tel.: +31(0)20525 1600

Tinbergen Institute Rotterdam

Burg. Oudlaan 50

3062 PA Rotterdam

The Netherlands

Tel.: +31(0)10 4088900

Fax: +31(0)10 4089031 


\title{
Redistributive Politics and the Tyranny of the Middle Class*
}

\author{
Floris T. Zoutman** $\quad$ Bas Jacobs ${ }^{* * *} \quad$ Egbert L.W. Jongen****
}

April 26, 2016

\begin{abstract}
The Netherlands has a unique tradition in which all major Dutch political parties provide CPB Netherlands Bureau for Economic Policy Analysis with highly detailed proposals for the taxbenefit system in every national election. This information allows us to quantitatively measure the redistributive preferences of political parties. For each political party we calculate social welfare weights by income level using the inverse optimal-tax method. We find that all political parties roughly give a higher social welfare weight to the poor than to the rich. Furthermore, left-wing parties attach higher social welfare weights to the poor and lower social welfare weights to the rich than right-wing parties do. However, we also discover two anomalies. First, all political parties give a much higher social welfare weight to middle incomes than to the working and non-working poor. Second, all Dutch political parties attach a slightly negative social welfare weight to the rich by setting top rates beyond the revenue-maximizing 'Laffer' rate. Finally, we detect a strong political status quo, since social welfare weights of all political parties hardly deviate from the welfare weights that are implied by the pre-existing tax-benefit system. We argue that political-economy considerations are key in understanding the political status quo and why middle-income groups are able to lower their tax burdens at the expense of both the low- and high-income groups.
\end{abstract}

Key words: Inverse optimal-tax method, revealed social preferences, political parties, optimal taxation, income redistribution

JEL Codes: C63, D63, H21

*This paper previously circulated under the title: "Revealed Social Preferences of Dutch Political Parties". We thank Nicole Bosch, Arjen Quist and Mathijn Wilkens for excellent research assistance. We have benefited from comments and suggestions by Olivier Bargain, Robin Boadway, Nathan Hendren, Laurence Jacquet, Etienne Lehmann, Erzo Luttmer, Andreas Peichl, Casey Rothschild, Dominik Sachs, Emmanuel Saez, Paul Tang, Matti Tuomala, Danny Yagan, Jinxian Wang, Matthew Weinzierl, and seminar and congress participants at CPB Netherlands Bureau for Economic Policy Analysis, Harvard University, University of California Berkeley, European University Institute, the IIPF 2011 in Ann Arbor, the CPB Workshop Behavioural Responses to Taxation and Optimal Tax Policy 2013 in the Hague, the ASSA 2015 Meetings in Boston, and BYU Computational Public Economics Conference 2015 in Park City. Remaining errors are our own. Zoutman gratefully acknowledges financial support from the Netherlands Organisation for Scientific Research (NWO) under Open Competition grant 400-09-383. The views expressed herein are those of the authors and do not necessarily reflect the views of CPB Netherlands Bureau for Economic Policy Analysis, Erasmus University Rotterdam, the Norwegian School of Economics, the Norwegian Center of Taxation, and Leiden University.

${ }^{* *}$ NHH Norwegian School of Economics, Department of Business and Management Science and Norwegian Center of Taxation. E-mail: floris.zoutman@nhh.no. Homepage: https://sites.google.com/site/flzoutman.

***Erasmus University Rotterdam, Tinbergen Institute, and CESifo. E-mail: bjacobs@ese.eur.nl. Homepage: http://people.few.eur.nl/bjacobs.

${ }^{* * * *}$ CPB Netherlands Bureau for Economic Policy Analysis and Leiden University. E-mail: e.l.w.jongen@cpb.nl. Homepage: http://www.cpb.nl/en/medewerkers/egbert-jongen. 
"Don't tell me what you value. Show me your budget, and I will tell you what you value." Joe Biden - US Presidential Elections, September 15, 2008

\section{Introduction}

As income and wealth inequality have been rising in many countries during recent decades (Atkinson et al., 2011; Piketty, 2014), income inequality has returned to the top of the political agenda. Indeed, President Obama (2013) has called inequality the 'defining challenge of our time' and political disputes over income redistribution have become more polarized and ideologically charged. Republicans accuse the Democrats of 'taxing job creators' (Romney, 2012), while Democrats often accuse the Republican Party of only cutting taxes for the very rich (Obama, 2015). Debates concerning redistribution are also strongly polarized in the Netherlands. Conservative-liberal Prime Minister Mark Rutte (2012) considers all left-wing parties 'socialist' that 'destroy wealth' by 'letting the government take away more than half of every euro you make'. ${ }^{1}$ Conversely, the Socialist Party has blamed the right-wing parties of pursuing 'neo-liberal' policies that only 'make the rich richer and the poor poorer' (Socialist Party, 2014). Similar examples can be found in many other countries. However, despite heated political rhetoric, no one has - to the best of our knowledge - ever tried to measure the redistributive preferences of political parties.

In this paper we measure the redistributive preferences of political parties by exploiting data on the tax-benefit proposals of political parties in their election programs. In a process unique in the world, CPB Netherlands Bureau for Economic Policy Analysis (CPB) makes an extensive analysis of the effects of election programs on public expenditures and tax revenues, key macroeconomic variables (economic growth, employment, inflation, etc.), and the income distribution for every national election in the Netherlands since $1986 .{ }^{2}$ To conduct this analysis, all major Dutch political parties voluntarily provide $\mathrm{CPB}$ with detailed policy proposals. CPB acts as a disciplinary device by preventing political parties presenting free lunches in their election programs. Moreover, CPB is widely considered, by political parties and the media alike, to be the single most important non-partisan judge regarding the economic consequences of political parties' policy proposals. The publication containing the economic outcomes of the election programs, Charting Choices, plays an important role in the election campaign. Politicians use the figures from Charting Choices to back up their arguments in election debates. Moreover, the election programs of Dutch political parties are not cheap talk. CPB's analyses of the different party programs are the basis for the negotiations among coalition parties forming a government after the elections. 92 percent of all measures of the most recent coalition government were announced previously in the election programs (Suyker, 2013)..$^{3}$

\footnotetext{
${ }^{1}$ In Europe, liberal parties are not left-wing oriented parties, but classical liberal, pro-market, small-government parties that generally take conservative positions on non-economic matters. That is why we consistently use the terminology 'conservative-liberal' parties in this paper.

${ }^{2}$ See CPB and PBL (2012) for the analysis of the 2012 elections, and the contributions in Graafland and Ros (2003) for the advantages and disadvantages of this practice.

${ }^{3}$ The current coalition government consists of the conservative-liberal party VVD and the social-democratic party
} 
Based on the data supplied to CPB we are able to reveal the social preferences for income redistribution by using the so-called inverse optimal-tax method, pioneered by Olivier Bargain, Francois Bourguignon and Amadeo Spadaro. ${ }^{4}$ The main idea is that each political party sets its tax-benefit system so as to maximize its political objectives for income redistribution. Political preferences for income redistribution can originate from ideological, strategic or opportunistic motives, on which we remain agnostic. By exploiting the detailed information on the proposed tax-benefit systems, and assuming that political parties indeed optimize the tax-benefit system according to their preferences, we are able to calculate the social welfare weights of Dutch political parties for all income groups and the non-employed. That is, we can calculate by how much social welfare would increase - measured in euros - when a particular political party transfers one euro to an individual belonging to a particular income group. Thus, to paraphrase Joe Biden, by showing their budgets, Dutch political parties tell us what they value.

We base our calculations on an inversion of the optimal-tax model for income taxation of Jacquet et al. (2013), which allows for both an intensive (hours or effort) and an extensive (participation) decision margin by households. We calibrate a structural version of the model using detailed information on: i) the earnings distribution, including an estimate of the Pareto tail for the top; ii) marginal and participation taxes derived from an advanced tax-benefit calculator incorporating all taxes and transfers in the Netherlands; iii) CPB-estimates of intensive and extensive elasticities that are used in the calculation of the long-run economic effects of the election programs. ${ }^{5}$ The inverse optimal-tax method allows us recover the social welfare weights implicit in the detailed proposals for the tax-benefit system of Dutch political parties in the elections of 2002. We focus on four political parties that fit into the 'left-wing' and 'right-wing' taxonomy regarding preferences for income redistribution: the socialist party $(\mathrm{SP})$, the labor party $(\operatorname{PvdA})$, the Christian-democratic party (CDA) and the conservative-liberal party (VVD). Our main findings are fourfold.

First, political preferences for income redistribution are partially congruent with standard social

PvdA. Although 92 percent of all measures taken come from either the VVD or PvdA election program, the budgetary size of the proposed measures changes due to coalition negotiations (Suyker, 2013).

${ }^{4}$ Studying the 'dual' problem of optimal taxation has a long history in public economics, see e.g. Stern (1977), Christiansen and Jansen (1978), Ahmad and Stern (1984), and Decoster and Schokkaert (1989). However, only recently have researchers been able to use detailed micro data on incomes and corresponding tax rates to study the social preferences implicit in tax-benefit systems. Bourguignon and Spadaro (2012) reveal the social preferences for income redistribution in the French tax-benefit system, using the inverse optimal-tax problem of Saez (2001) with an intensive decision margin, and the inverse optimal-tax problem of Saez (2002) with both an intensive and an extensive decision margin. Blundell et al. (2009) consider the social welfare weights of single mothers in the UK and Germany, and estimate, rather than calibrate, the intensive and extensive elasticities using micro data and a discrete-choice labor-supply model. Bargain and Keane (2011) calculate social welfare weights for Ireland and the UK at different points in time, ranging from 1987 to 2005. Bargain et al. (2014) conduct a similar analysis for singles in 17 European countries. Lockwood and Weinzierl (2016) study the evolution of welfare weights in the US over the period 1979-2010. Hendren (2014) shows that welfare weights can be used to make interpersonal comparisons without using a social welfare function. Social welfare weights therefore allow policy makers to consider reforms in a framework that does not force them to make normative judgments. Lorenz and Sachs (2016) use the inverse optimal-tax method to identify whether social welfare weights are negative and, hence, whether Pareto-improving tax reforms exist in Germany. However, none of these papers calculates social welfare weights for political parties.

${ }^{5}$ These estimates are in line with most recent causal evidence of the elasticity of taxable income and participation elasticities in the literature. 
welfare functions featuring declining social welfare weights with income. ${ }^{6}$ In particular, all parties roughly give a higher social welfare weight to the poor than to the rich. And, left-wing parties give a higher social welfare weight to the poor and a lower social welfare weight to the rich than right-wing parties do. Dutch political parties approximately give an equal weight to the working poor and the non-employed.

Second, we detect an important and robust anomaly in that social welfare weights are increasing from the working poor to the middle-income groups in the pre-existing tax-benefit system, as well as in all political party programs. This means that Dutch political parties consider reverse income redistribution - away from the working poor towards the middle class - welfare-improving. This result arises from the fact that effective marginal tax rates are gradually increasing up to modal income in the pre-existing tax-benefit system and this remains so in all election proposals. Increasing marginal tax rates are at odds with the optimal-tax literature. For incomes below the mode of the income distribution, effective marginal tax rates should decline with income if welfare weights are decreasing with income (Diamond, 1998).

Third, we uncover a second anomaly. All political parties give a negative social welfare weight to the rich, since they set the top rate of the income tax beyond the 'Laffer' rate. This implies that the Dutch government taxes the rich too much. Slightly lowering the top rate thus generates a Pareto-improvement with larger income redistribution and higher economic efficiency. This finding is sensitive to the elasticity of taxable income at the top, and would disappear if the elasticity would be lower. Nevertheless, given the best empirical evidence available on the elasticity of taxable income for top-income earners, we are fairly confident to conclude that all Dutch political parties set top rates at levels that completely 'soak the rich'.

Fourth, we uncover a very strong status-quo bias in redistributive politics in the Netherlands. The cross-party differences in social welfare weights are very small and closely aligned with the welfare weights from the pre-existing tax-benefit system. This finding demonstrates that the heated political debates on income redistribution are mostly hot air.

According to John Adams, one of the founding fathers of the US, democracy can be characterized as the tyranny of the majority. Three of our main findings - increasing welfare weights to the middle, top rates that soak the rich, and a strong status-quo bias - suggest that the Dutch democracy can be characterized as the 'tyranny' of the middle class.

Our paper provides three methodological contributions to the inverse optimal-tax literature. First, our study is the first to derive the social welfare weights in a continuous-type model while allowing for both intensive and extensive earnings margins. Second, we allow for income effects. Previous studies only analyzed social welfare weights in discrete-type models assuming away income effects (e.g., Bargain and Keane, 2011; Bourguignon and Spadaro, 2012; Bargain et al., 2013). Third, we derive expressions for the social welfare weights in terms of sufficient statistics for the Jacquet et al. (2013)-model with intensive and extensive margins. The sufficient-statics formulae

\footnotetext{
${ }^{6}$ Typically, social welfare weights smoothly decline with income due to diminishing marginal utility of private income or concavity in the social welfare function.
} 
for social welfare weights allow researchers to calculate the social welfare weights implied by any tax-benefit system using data on the earnings distribution, tax rates, and elasticities for earningssupply and participation. By using a structural model in our simulations, we demonstrate that the sufficient-statistics approach provides an excellent approximation to the welfare weights obtained from the structural model.

Our method to measure political preferences for income redistribution provides a bridge between political economics and normative public finance. Our approach gives empirical support for some well-known political-economy theories. The importance of middle-income groups in determining income redistribution is established in standard political models of income redistribution in which the median voter determines the linear income tax (Romer, 1975; Roberts, 1977; Meltzer and Richard, 1981). Röell (2012) and Brett and Weymark (2014) generalize these models to the political economy of non-linear income taxation in citizen-candidate models. By allowing for nonlinear instruments, Brett and Weymark (2014) demonstrate that the middle-income groups are able to protect their self-interest at the expense of both the low- and the high-income groups. The patterns of the social welfare weights that we detect - increasing to modal incomes and sharply decreasing thereafter - are also in line with Director's law, where the middle-income groups form a successful coalition against the low- and high-income groups (Stigler, 1970). Furthermore, the high welfare weights for the middle-income groups could be explained by two-dimensional political competition. Probabilistic-voting models might explain why even left-wing parties might sacrifice some of their redistributive goals if this helps to achieve larger electoral success by attracting voters on other, ideological positions (Persson and Tabellini, 2000; Bierbrauer and Boyer, 2016). Alternatively, Roemer $(1998,1999)$ studies models of within-party conflict between ideological and opportunistic party factions, which might also explain why political parties deviate from their ideological positions. Also, post-election considerations could explain the strong status-quo bias in announced tax-benefit plans. Political parties may deliberately want to avoid highly pronounced party positions, since they need to form a coalition government with other parties after the elections (Persson and Tabellini, 2000). Finally, the strong status-quo bias that we find, but also the persistence of various findings across all parties, could also be explained by vested interests blocking welfare-improving tax-benefit reforms (Olson, 1982).

The outline of the paper is as follows. Section 2 introduces the optimal tax model, derives the expressions for optimal taxes and social welfare weights, and explains the conditions under which the social welfare weights are non-negative and decreasing with income. Section 3 discusses the data on the Dutch income distribution, the tax and benefit system, and the elasticities that are used to calibrate the model. Section 4 analyzes the tax-benefit proposals of the political parties. Section 5 derives the social welfare weights in the pre-existing tax-benefit system and in the proposals of Dutch political parties. Section 6 explains how political-economy considerations may explain the patterns in the social welfare weights that we detect. Section 7 concludes. An Appendix contains the proofs of the propositions, background information regarding the Dutch tax-benefit system and the Dutch political system, and the estimation, calibration and simulation procedures. 


\section{Model}

This section introduces the model, derives the optimal tax-benefit system and the formulae for the social welfare weights using the optimal-tax model of Jacquet et al. (2013). These authors combine the Mirrlees (1971) model of optimal income taxation with only an intensive labor-supply margin with the Diamond (1980) model of optimal income taxation with only an extensive labor-supply margin. We contribute to Jacquet et al. (2013) by expressing the optimal income and participation taxes fully in terms of sufficient statistics - up to the social welfare weights - , whereas the results of Jacquet et al. (2013) are derived in terms of non-observable distributions of ability and participation costs. Moreover, we derive an expression for the optimal participation tax similar to that of Saez (2002). We also generalize earlier literature on the inverse optimal-tax method in two ways (see e.g. Saez, 2002, Bourguignon and Spadaro, 2012, Bargain and Keane, 2011, and Bargain et al., 2013). First, we allow for income effects on the intensive margin. Second, we allow for continuous skill types with both intensive and extensive earnings-supply responses. Earlier literature with both intensive and extensive margins only analyzed the discrete-choice model of Saez (2002).

\section{$2.1 \quad$ Individuals}

Following Jacquet et al. (2013), individuals differ in their earnings ability $n$, and utility costs of participation $\varphi$. Both characteristics are private information and their joint density function is given by $k(n, \varphi)$ with support $[\underline{n}, \bar{n}] \times[\underline{\varphi}, \bar{\varphi}]$, where $0<\underline{n}<\bar{n} \leq \infty$ and $-\infty \leq \underline{\varphi}<\bar{\varphi} \leq \infty$. Earnings ability reflects the productivity per hour worked, as in Mirrlees (1971). $\varphi$ is an idiosyncratic utility cost (or benefit), which reflects an individual-specific cost from participation, for example foregone leisure time or household production, or the cost of commuting to work, see also Diamond (1980). Participation costs can also be negative, for example because of the value of social contacts at work or by avoiding the stigma of being non-employed. We will express all optimal tax rules in terms of the observable earnings distribution $F(z)$, with its corresponding density function $f(z)$, rather than in terms of the unobserved distribution $k(n, \varphi)$.

Employed individuals with ability $n$ derive utility from consumption $c_{n}$, disutility from earnings supply $z_{n}$, and disutility from participation $\varphi$. The utility function of a working individual with ability $n$ and participation costs $\varphi$ equals

$$
U_{n, \varphi} \equiv u(c, z, n)-\varphi, \quad u_{c},-u_{z}, u_{n}>0, \quad u_{c c}, u_{z z} \leq 0, \quad \forall n, \varphi
$$

where $u(\cdot)$ is differentiable, increasing, and weakly concave in consumption $c$ and differentiable, increasing, and concave in earnings supply $z$. If labor earnings are the product of labor supply $l$ and ability $n$, so that $z \equiv n l$, individuals with a higher ability $n$ obtain a given level of earnings $z$ with lower labor supply $l .{ }^{7}$

\footnotetext{
${ }^{7}$ The formulation by Mirrlees (1971) is obtained if skill types are perfect substitutes in production, the utility function is the same across individuals, and the wage rate per efficiency unit of labor equals unity. Hence, gross labor earnings equal $z_{n}=n l_{n}$, and utility can be written as $u\left(c_{n}, l_{n}\right)$.
} 
Labor earnings and employment status are verifiable to the government. Hence, the government can condition taxes and transfers on gross labor income $z$ and the individual's employment status. The income tax function is non-linear, continuous, differentiable, and denoted by $T(z)$, where $T^{\prime}(z) \equiv \mathrm{d} T(z) / \mathrm{d} z$ is the marginal tax rate. All net labor income is spent on consumption $c$. Consequently, the individual budget constraint is $c=z-T(z)$. Non-employed workers receive a non-employment benefit $b$, which generally differs from the net income of employed workers earning zero income $-T(0)$. Hence, the non-employed enjoy consumption $c=b$, while they do not provide any earnings effort (i.e., $z=0$ ). The maximization problem for employed individuals is given by: $\max _{z} u(z-T(z), z, n)$, where we have substituted the budget constraint in the utility function. The first-order condition is the same as in the standard Mirrlees (1971) model:

$$
\frac{-u_{z}(\cdot)}{u_{c}(\cdot)}=1-T^{\prime}(z), \quad \forall n
$$

A non-employed individual derives utility from consuming non-employment benefits $b: v(b) \equiv$ $u(b, 0)$. Consequently, an individual decides to participate in the labor market if her maximized utility when working is larger than the utility obtained from being non-employed: $u-\varphi>v(b)$. The employment rate at each income level $z$ equals the employment rate at each ability level $n$ in view of the perfect mapping between ability $n$ and earnings $z$ for workers: $E_{z} \equiv E_{n} \equiv \int_{\underline{\varphi}}^{u-v(b)} k(n, \varphi) \mathrm{d} \varphi$. $E_{z}$ thus depends on the joint distribution $k(n, \varphi)$, the benefit level $b$, and the tax function $T(z)$. For later reference, we define the participation tax rate $\tau_{z}$ at income level $z$ as $\tau_{z} \equiv(T(z)+b) / z$.

\subsection{Incentive compatibility}

The allocation is incentive compatible if the following first-order incentive-compatibility constraint holds:

$$
\frac{\mathrm{d} u}{\mathrm{~d} n}=u_{n}(c, z, n)
$$

This condition can be derived by totally differentiating utility (1) with respect to ability $n$ and using the first-order condition for earnings supply (2). The incentive-compatibility constraint (3) does not depend on participation costs. Intuitively, a worker with ability $n$ has to incur participation $\operatorname{cost} \varphi$ irrespective of whether the worker self-selects in the consumption-income bundle for type $n$ or decides to mimic a worker of type $m$ to obtain the consumption-income bundle intended for type $m$. We use the first-order approach using (3), assuming that the second-order conditions are satisfied. Second-order sufficiency conditions for utility maximization are met if the Spence-Mirrlees

and monotonicity constraints are satisfied: $\mathrm{d}\left(\frac{u_{z}(\cdot)}{u_{c}(\cdot)}\right) / \mathrm{d} n \leq 0$ and $\mathrm{d} z_{n} / \mathrm{d} n>0 \forall n$, see also Ebert (1992). In our simulations we check ex post whether the second-order sufficiency conditions are indeed fulfilled, which is always the case. 


\subsection{Government}

The government's redistributive preferences are captured by a set of exogenously given marginal social welfare weights $g$ for all individuals, as in Saez and Stantcheva (2016). $g_{z}$ measures the monetized gain in social welfare of providing one unit of income to a particular individual with income $z$. Similarly, $g_{0}$ is the welfare weight of the non-employed. The average social welfare weight of all working individuals at income level $z$ is represented by $g_{z} \equiv \frac{\int_{\varphi}^{u-v(b)} g_{z, \varphi} k(n, \varphi) \mathrm{d} \varphi}{\int_{\underline{\varphi}}^{u-v(b)} k(n, \varphi) \mathrm{d} \varphi}$, where $g_{z, \varphi}$ is the social welfare weight of an individual with earnings $z$ and participation costs $\varphi .{ }^{8}$

The government budget constraint states that total tax revenue from individuals that are employed equals outlays on transfers $b$ for the non-employed, and a revenue requirement $R$ :

$$
\int_{\underline{n}}^{\bar{n}} \int_{\underline{\varphi}}^{u-v(b)} T(z) k(n, \varphi) \mathrm{d} \varphi \mathrm{d} n=(1-E) b+R,
$$

where $E \equiv \int_{\underline{n}}^{\bar{n}} \int_{\underline{\varphi}}^{u-v(b)} k(n, \varphi) \mathrm{d} \varphi \mathrm{d} n$ is the aggregate employment rate.

The government minimizes resources $R$ in (4) by optimally choosing the non-linear tax function $T(z)$ and the non-employment benefits $b$ subject to incentive constraints (3) and a distributional constraint, which specifies an exogenously given level of utility for each individual, see Jacquet et al. (2013).

\subsection{Optimal tax-benefit schedule and social welfare weights}

\subsubsection{Optimal tax-benefit system}

The optimal non-linear income tax and participation tax rates are given in the following proposition.

Proposition 1 The optimal non-linear income tax schedule and the optimal participation tax rate are determined by

$$
\begin{gathered}
\frac{T^{\prime}(z)}{1-T^{\prime}(z)}=\underbrace{\frac{1}{\varepsilon_{z}^{c}} \int_{\equiv B_{z}}^{\int_{z}^{\bar{z}}\left(1-g_{\tilde{z}}+\eta_{\tilde{z}} \frac{T^{\prime}(\tilde{z})}{\left(1-T^{\prime}(\tilde{z})\right)}-\zeta_{\tilde{z}}^{T} \frac{\tau_{\tilde{z}}}{\left(1-\tau_{\tilde{z}}\right)}\right) f(\tilde{z}) \mathrm{d} \tilde{z}} \underbrace{\frac{(1-F(z))}{f(z) z}}_{\equiv C_{z}}, \forall z,}_{\equiv A_{z}} \\
E \int_{\underline{z}}^{\bar{z}} \zeta_{\tilde{z}}^{b} \frac{\tau_{\tilde{z}}}{\left(1-\tau_{\tilde{z}}\right)} f(\tilde{z}) \mathrm{d} \tilde{z}=(1-E)\left(g_{0}-1\right) .
\end{gathered}
$$

where $\varepsilon_{z}^{c} \equiv-\frac{\partial z}{\partial T^{\prime}} \frac{\left(1-T^{\prime}\right)}{z}>0$ is the compensated elasticity of taxable income with respect to the marginal income tax rate, $\eta_{z} \equiv-\left(1-T^{\prime}\right) \frac{\partial z}{\partial \rho} \geq 0$ is the income elasticity of earnings supply, $\zeta_{z}^{T} \equiv-\frac{\partial E_{z}}{\partial \tau_{z}} \frac{\left(1-\tau_{z}\right)}{E_{z}}$ is the participation elasticity with respect to the participation tax rate when the

\footnotetext{
${ }^{8}$ For example, when social welfare is given by a Bergson-Samuelson social welfare function $W\left(U_{n, \varphi}\right)$, where $W^{\prime}>$ $0, W^{\prime \prime} \leq 0$, the social welfare weight of a worker with earning ability $n$ and participation costs $\varphi$ equals $g_{n, \varphi} \equiv$ $W^{\prime}(\cdot) u_{c}(\cdot) / \lambda$, where $\lambda$ denotes the shadow value of public funds.
} 
income tax changes, $\zeta_{z}^{b} \equiv-\frac{\partial E_{z}}{\partial \tau_{z}} \frac{\left(1-\tau_{z}\right)}{E_{z}}$ is the participation elasticity with respect to the participation tax rate when the benefit level changes.

Proof. See Appendix A.

Equation (5) is a simplification of the original optimal-tax formula in Jacquet et al. (2013). We contribute to their analysis by expressing the optimal-tax formula entirely in terms of measurable sufficient statistics. We also generalize the $A B C$-formula of Diamond (1998) and Saez (2001) to include the extensive margin. Moreover, we do not need to rely on virtual densities for earnings as in Saez (2001). ${ }^{9}$ The intuition for the optimal income tax expression is well explained in Diamond (1998), Saez (2001, 2002), and Jacquet et al. (2013). Only one feature of the optimal income tax is important to understand our later findings: the marginal income tax schedule in the Netherlands is gradually increasing rather than U-shaped. This pattern of marginal tax rates can only be explained by increasing social welfare weights towards the mode. The reason is that in our simulations, the $A_{z}$-term is nearly constant and the $C_{z}$-term always falls until the mode as its numerator declines and its denominator increases. ${ }^{10}$ Hence, the $B_{z}$-term must be strongly increasing towards the mode to off-set the impact of the declining $C_{z}$-term.

Equation (6) gives the optimality condition for the optimal participation tax in terms of sufficient statistics, which resembles the optimal participation tax in the discrete-type model of Saez (2002). ${ }^{11}$ In the optimum, the marginal benefits of redistributing income from the employed to the nonemployed (right-hand side) should be equal to the marginal costs of doing so (left-hand side). If the government raises the participation tax by increasing non-employment benefits $b$ by 1 unit of income, then $g_{0}-1$ gives the mechanical welfare gain minus the mechanical cost of this marginal increase in $b$. The welfare weight of the non-employed $g_{0}$, i.e., the individuals who are worst off, is typically larger than 1 , since the average welfare weight is approximately one. ${ }^{12}$ Redistribution towards the non-employed is more valuable, the larger is the number of non-employed, i.e., the lower is $E$. The left-hand side of equation (6) captures the total participation distortions. $\zeta_{z}^{b} \frac{\tau_{z}}{\left(1-\tau_{z}\right)}$ is the social cost of lower participation when the non-employment benefit $b$ is raised as some individuals with income $z$ now stop paying taxes and start collecting non-employment benefits. The social cost of the participation tax increases in the participation elasticity $\zeta_{z}^{b} \cdot{ }^{13}$ Participation distortions are more important when the number of employed workers $E$ is larger.

\footnotetext{
${ }^{9}$ Saez (2001) conjectures and Jacquet and Lehmann (2015) prove that the Mirrlees model is applicable as well under preference heterogeneity. In that case, the elasticities at each income level represent the averages of the elasticities over all individuals at each income level. Our model preserves this property as long as individuals make only one choice on the intensive margin, while retaining the random-participation structure.

${ }^{10}$ After the mode, the behavior of $C_{z}$ becomes theoretically ambiguous. Empirically, however, the $C_{z}$-term increases after the mode in many countries, see also Saez (2001).

${ }^{11}$ See also equation (18d) in Jacquet et al. (2013, p.1781).

${ }^{12}$ The average social welfare weight is exactly one in the absence of income effects and when participation elasticities are the same for tax and benefit changes.

${ }^{13}$ Due to income effects in participation choices the participation elasticity of a benefit increase $\zeta_{z}^{b}$ is generally not equal to the participation elasticity of a tax increase $\zeta_{z}^{T}$. Both elasticities coincide when utility is quasi-linear or when participation costs are monetary.
} 


\subsubsection{Social welfare weights}

The inverse-optimal tax method asks the question: which set of social welfare weights makes that particular tax-benefit system the optimal one (Bourguignon and Spadaro, 2012)? The answer is found by solving the expressions for the optimal income tax and benefit levels in Proposition 1 for social welfare weights $g_{z}$ and $g_{0}$ in Proposition 2 .

Proposition 2 The social welfare weights associated with any optimized tax-benefit system satisfy

$$
\begin{gathered}
g_{z}=1+\frac{1}{f(z)} \frac{\partial D W L_{z}}{\partial z}+\eta_{z} \frac{T^{\prime}(z)}{\left(1-T^{\prime}(z)\right)}-\zeta_{z}^{T} \frac{\tau_{z}}{\left(1-\tau_{z}\right)}, \quad \forall z \\
\frac{1}{f(z)} \frac{\partial D W L_{z}}{\partial z} \equiv\left(\xi_{z}+\theta_{z}\right) \varepsilon_{z}^{c} \frac{T^{\prime}(z)}{1-T^{\prime}(z)}+\varepsilon_{z}^{c} \frac{z T^{\prime \prime}(z)}{\left(1-T^{\prime}(z)\right)^{2}}, \quad \forall z, \\
g_{0}=1+\frac{E}{(1-E)} \int_{\underline{z}}^{\bar{z}} \zeta_{\tilde{z}}^{b} \frac{\tau_{\tilde{z}}}{\left(1-\tau_{\tilde{z}}\right)} f(\tilde{z}) \mathrm{d} \tilde{z},
\end{gathered}
$$

where $D W L_{z} \equiv \varepsilon_{z}^{c} \frac{T^{\prime}(z)}{\left(1-T^{\prime}(z)\right)} z f(z)$ is the marginal deadweight loss on tax base $z f(z), \xi_{z} \equiv \frac{\partial \varepsilon_{z}^{c}}{\partial z} \frac{z}{\varepsilon_{z}^{c}}$ is the elasticity of the compensated elasticity of taxable income, and $\theta_{z} \equiv 1+\frac{z f^{\prime}(z)}{f(z)}$ denotes the elasticity of the local tax base $z f(z)$ with respect to income $z$.

Proof. See Appendix B.

Equation (7) shows that the social welfare weights are based on sufficient statistics only by using information on marginal and participation tax rates, compensated and income elasticities of earnings supply, participation elasticities, and the earnings distribution. Social welfare weights for the non-employed $g_{0}$ in equation (9) are larger the more the government distorts participation, since participation is distorted only to redistribute income from the employed to the non-employed. Note that all welfare weights are equal to one $\left(g_{z}=1\right)$ if marginal and participation tax rates are zero. When the government does not engage in any income redistribution through distortionary taxation, it must attach the same welfare weight to everyone. In the analysis that follows we are particularly interested in whether social welfare weights are: i) monotonically declining in income, so that political parties always care more about poorer than richer individuals, ii) always positive, since otherwise Pareto-improving tax reforms exist, and iii) feature discontinuous jumps, so that large differences in social welfare weights exist for individuals differing only marginally in income, which, too, suggests the possibility of welfare-improving tax reforms.

Behavior of social welfare weights with income. The most important determinant of the social welfare weights in equation (7) is the change of the deadweight loss $D W L_{z}$ with earnings $z$. $\varepsilon_{z}^{c} \frac{T^{\prime}(z)}{\left(1-T^{\prime}(z)\right)}$ stands for the marginal deadweight loss per unit of tax base at income level $z$, and $z f(z)$ is the size of the tax base at $z$. Intuitively, if the deadweight losses are increasing at income level $z$, then the government redistributes from individuals with incomes higher than $z$ to individuals with income levels below $z$. Consequently, social welfare weights for individuals at income $z$ are 
higher than for individuals above income $z{ }^{14}$ The change in the deadweight loss is larger when both marginal tax rates $T^{\prime}(z)$ or elasticities $\varepsilon_{z}^{c}$ are higher - for given $\theta_{z}$ and $\xi_{z}$.

To gain more insights into the behavior of social welfare weights with income, we follow Diamond (1998). Suppose income and participation effects are zero $\left(\eta_{z}=\zeta_{z}^{T}=0\right)$ and intensive earningssupply elasticities are constant $\left(\varepsilon_{z}^{c} \equiv \varepsilon^{c}\right) .{ }^{15}$ Our quantitative results show that these terms indeed have a negligible impact on the social welfare weights. ${ }^{16}$ The social welfare weights can then be simplified to:

$$
g_{z}=1+\theta_{z} \varepsilon^{c} \frac{T^{\prime}(z)}{\left(1-T^{\prime}(z)\right)}+\varepsilon^{c} \frac{z T^{\prime \prime}(z)}{\left(1-T^{\prime}(z)\right)^{2}}, \quad \forall z
$$

and the change of the social welfare weights with respect to gross earnings equals:

$$
\frac{\partial g_{z}}{\partial z}=\left(1+\theta_{z}\right) \varepsilon^{c} \frac{T^{\prime \prime}(z)}{\left(1-T^{\prime}(z)\right)^{2}}+\varepsilon^{c} \frac{T^{\prime}(z)}{\left(1-T^{\prime}(z)\right)} \frac{\partial \theta_{z}}{\partial z}+\varepsilon^{c} z\left(\frac{T^{\prime \prime \prime}(z)}{\left(1-T^{\prime}(z)\right)^{2}}+2 \frac{\left(T^{\prime \prime}(z)\right)^{2}}{\left(1-T^{\prime}(z)\right)^{3}}\right) .
$$

From this we see that the behavior of social welfare weights with income is determined by two variables: the elasticity $\theta_{z}$ (and its derivative $\frac{\partial \theta_{z}}{\partial z}$ ) and the marginal tax rate $T^{\prime}(z)$ (and its derivative $\left.T^{\prime \prime}(z)\right)$. A higher elasticity $\varepsilon^{c}$ does not change these comparative statics, only their size. Hence, we expect to see that the patterns of social welfare weights become more pronounced when the elasticity of taxable income increases.

The behavior of the elasticity of the tax base $\theta_{z}$ is the key determinant of the social welfare weights. If $\theta_{z}$ is larger, marginal tax rates generate larger deadweight losses. Hence, the government attaches a higher social welfare weight to individuals with income above $z$ then to individuals at $z$ - ceteris paribus. Figure 1 plots the behavior of $\theta_{z}$ against gross income based for the Netherlands. $\theta_{z}$ changes non-monotonically with income: it first increases until it reaches a maximum at around the 25th percentile, after which it starts to decrease until it becomes a constant when the Pareto tail starts (at about 60,000 euro). ${ }^{17}$ Figure 1 shows that for the Dutch income distribution, $\theta_{z}$ is larger than -1 up to the 50th percentile, hence $1+\theta_{z}>0$ until the median. In the Netherlands, marginal tax rates also increase with earnings (i.e., $T^{\prime \prime}(z)>0$ ) up to the median. Therefore, the first term in (11) is positive up to the median. The second term in (11), the derivative of the elasticity of the tax base, is roughly positive up to the 30th percentile, and negative thereafter,

\footnotetext{
${ }^{14}$ Alternatively, if the welfare weights are expressed in terms of the Diamond (1975)-based social marginal value of income $g_{z}^{*} \equiv g_{z}-\eta_{z} \frac{T^{\prime}(z)}{\left(1-T^{\prime}(z)\right)}+\varepsilon_{z}^{P} \frac{\tau_{z}}{\left(1-\tau_{z}\right)}-$ which includes the income and participation effects on taxed bases optimality of the tax system implies that $g_{z}^{*}=1+\frac{1}{f(z)} \frac{\partial D W L_{z}}{\partial z}$ so that the Diamond-based social welfare weights are only determined by the change in the deadweight loss.

${ }^{15}$ Income effects on the intensive margin $\eta_{z} \frac{T^{\prime}(z)}{\left(1-T^{\prime}(z)\right)}$ raise the distributional benefits of a higher marginal tax rate, and thus raise social welfare weights - ceteris paribus. Participation distortions $\zeta_{z}^{T} \frac{\tau_{z}}{\left(1-\tau_{z}\right)}$ can either be positive or negative depending on whether the government taxes or subsidizes participation at income $z$. If $\tau_{z}>0$, participation distortions reduce the redistributional benefits of a higher marginal tax rate, hence social welfare weights are lower - ceteris paribus. The reverse is true when $\tau_{z}<0$.

${ }^{16}$ If $\xi_{z}>0\left(\xi_{z}<0\right)$ the government attaches a higher welfare weight to individuals with income $z$ than to those above $z$-ceteris paribus. Appendix D shows that intensive elasticities are roughly constant with income in our calibration. Hence, $\xi_{z}$ is approximately zero and is not important to explain the behavior social welfare weights.

${ }^{17}$ The empirical earnings distribution is supplemented with an estimated Pareto tail for the top income earners. If the earnings distribution $f(z)$ is Pareto with parameter $a$, then it can be written as $f(z)=a \hat{z}^{a} z^{-1-a}$, where $\hat{z}$ is the income level at which the Pareto distribution starts. Consequently, the elasticity of $z f(z)$ equals $-a$.
} 


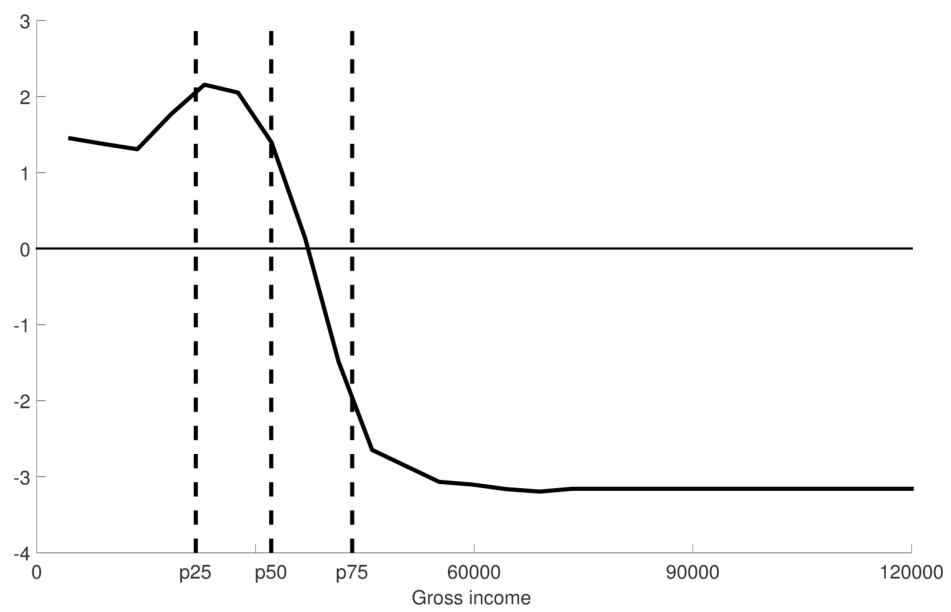

Figure 1: Elasticity of the tax base $\theta_{z}$

see Figure 1, where $\theta_{n}$ first increases and then decreases with income. Finally, the third term in (11) captures how changes in the marginal tax rates affect social welfare weights. The contribution of these terms is generally small, except around spikes in marginal tax rates. Therefore, in the Netherlands one expects to find increasing social welfare weights that are increasing up to at least the 30th percentile of the earnings distribution.

Negative social welfare weights. Whether social welfare weights are positive is especially relevant for the top-income earners. Atkinson et al. (2011) show that the Pareto distribution with parameter $a$ generally gives an excellent fit for the right tail of the income distribution. If we realistically assume that participation elasticities are negligible for top earners $\left(\zeta_{z}^{T}=0\right)$, and that compensated and income elasticities are constant $\left(\varepsilon_{z}^{c}=\varepsilon^{c}, \eta_{z}=\eta, \xi_{z}=0\right)$, optimal top rates are constant, and social welfare weights for top earners $g_{\infty}$ are given by:

$$
g_{\infty}=1-\left(a \varepsilon^{c}-\eta\right) \frac{T^{\prime}(\infty)}{1-T^{\prime}(\infty)}
$$

Social welfare weights for top income earners are non-negative, i.e. $g_{\infty} \geq 0$, when the marginal tax rate satisfies $T^{\prime}(\infty) \leq \frac{1}{1+a \varepsilon^{c}-\eta}$. When the latter inequality is strict, marginal tax rates are set at the top of the Laffer curve. Setting top rates beyond the Laffer rate is non-Paretian, since a reduction of top rates would both raise utility for top income earners, and raise tax revenue, which can be redistributed to make other individuals better off (Werning, 2007, Brendon, 2013, Lorenz and Sachs, 2016).

Spikes in social welfare weights. Social welfare weights display discontinuities if political parties generate spikes in marginal tax rates over small income intervals. These spikes are anomalous, since they generate large differences in social welfare weights for individuals differing only slightly in their earnings. The term $\frac{T^{\prime \prime \prime}(z)}{\left(1-T^{\prime}(z)^{2}\right.}+2 \frac{\left(T^{\prime \prime}(z)\right)^{2}}{\left(1-T^{\prime}(z)\right)^{3}}$ in equation (11) captures the influence of spikes in marginal tax rates on social welfare weights. There will be large changes in welfare weights if 
marginal tax rates change a lot in narrow income intervals. When marginal tax rates do not change much with income, this term is small, since then we have $\left(T^{\prime \prime}(z)\right)^{2} \approx T^{\prime \prime \prime}(z) \approx 0$.

\section{Calibration}

\subsection{Structural model}

This section explains in detail the data used in our analysis and the calibration of our model. We develop a structural version of the model because the elasticities, the income distribution and the employment rates are endogenous to the policy proposals of political parties, which could potentially bias our findings, see also Chetty (2009). By employing a structural approach, we take these endogeneities into account. However, our structural model may also be sensitive to specification errors. We can avoid such specification errors by using the sufficient-statistics approach, which does not require any knowledge of the 'deep' parameters of our model, i.e. the utility function and the distributions of ability and participation costs. In our analysis we compare the welfare weights derived under both approaches.

Appendix $\mathrm{C}$ shows that the utility function $u(c, z, n)$, the joint distribution function of ability and participation costs $k(n, \varphi)$, and the allocation $\{c, z\}$ yield the necessary information to calculate the social welfare weights associated with any tax-benefit system $\{T(z), b\}$. We identify the structural model by estimating the joint distribution of ability and participation costs $k(n, \varphi)$, calibrating the utility function $u(c, z, n)$ on empirically estimated intensive and extensive elasticities, and using the tax-benefit system in the baseline.

We make two important assumptions. First, we assume that ability and participation costs are independent. Hence, the joint distribution can be written as $k(n, \varphi) \equiv \hat{k}(n) h(\varphi)$, where $\hat{k}(n)$ is the density function of ability and $h(\varphi)$ is the density function of participation costs. We invert the individuals' first-order conditions to solve for their ability $n$. Then, we estimate a non-parametric

kernel regression for the distribution of ability $\hat{k}(n)$. Second, we estimate $h(\varphi)$ using data on employment rates by education and participation elasticities by income. More details on the exact calibration procedure can be found in Appendix C.

The remainder of this section describes the data to calibrate the model: i) the earnings distribution, ii) the tax-benefit system, iii) intensive elasticities, and iv) participation costs and extensive elasticities.

\subsection{Earnings distribution}

We calibrate the distribution of ability $\hat{k}(n)$ by inverting the individuals' first-order condition for earnings supply in the spirit of Saez (2001). To do so, we need information on earnings, tax rates, and elasticities. We use the micro data set and elasticities of taxable income used by CPB in the analysis of the 2002 election proposals. The 2002 election proposals concern the cabinet period 2003-2006. We recover the social welfare weights for 2006, the final year of the analysis when the full reform packages were projected to be implemented. 
The earnings data come from the Housing Demand Survey (HDS) (1998) - in Dutch: Woningbehoefteonderzoek - collected by Statistics Netherlands (1999). HDS 1998 contains sampling weights, which we use throughout the analysis. For the 2002 elections, CPB has updated the income data from the HDS 1998 to the year 2006, which we use as the baseline. We employ gross wage income as our definition of income and restrict the sample to employees. ${ }^{18}$ Our data set consists of 29,229 individuals. Figure 2 plots a kernel density estimate of the earnings distribution, using a bandwidth of 5,000 euro.

Since there are relatively few observations in the top tail of the earnings distribution in HDS 1998, we replace the top of the earnings distribution by a Pareto distribution. We use the method of Clauset et al. (2009) to simultaneously estimate the starting point of the Pareto distribution and the Pareto parameter, on the (uncensored) Income Panel 2002 - in Dutch: Inkomenspanel 2002 from Statistics Netherlands (2007). The estimated Pareto parameter is 3.158 and the estimated start of the Pareto distribution is 56,571 euro. The Pareto-parameter for the skill distribution is then calculated as $a\left(1+\varepsilon^{u}\right)$ where $\varepsilon^{u} \equiv \frac{\partial z}{\partial n} \frac{n}{z}$ is the uncompensated elasticity of earnings $z$ with respect to the skill level $n$ (wage per hour worked), see also Saez (2001, p.222).

\subsection{Tax-benefit system}

The social welfare weights are critically determined by the parameters of tax-benefit system. Therefore, it is important to use precise estimates for marginal tax rates and participation tax rates. ${ }^{19} \mathrm{We}$ calculate effective marginal tax rates (EMTRs) and participation tax rates (PTRs) using MIMOS2, the official tax-benefit calculator of CPB used in the analysis of the 2002 election proposals. ${ }^{20}$ To calculate the EMTR we first increase individual gross wage income by 3 percent. Next, we determine the corresponding increase in disposable household income. Finally, the EMTR is calculated as 1 minus the increase in disposable household income over the increase in gross wage income. MIMOS-2 takes into account all relevant income-dependent tax rates, tax credits and subsidies to calculate the EMTRs in the Netherlands. ${ }^{21}$ Furthermore, we also include indirect taxes into our measure of effective marginal tax rates. ${ }^{22}$ According to the National Accounts of Statistics Netherlands, indirect taxes on private consumption are 12.0 percent of private consumption in $2006 .^{23}$ We assume that indirect taxes - of which the VAT is the most important one - are a con-

\footnotetext{
${ }^{18}$ We obtain similar results when we use labor costs instead of gross wages, and when we include self-employed and (positive) profit income.

${ }^{19}$ Moreover, by precisely calculating marginal tax rates, we also improve on Saez (2001) and Jacquet et al. (2013). They assume a flat marginal tax rate to retrieve the ability distribution when inverting the individual first-order conditions. Since actual tax schedules are not linear, this procedure may bias the estimate for the ability distribution.

${ }^{20}$ A detailed description (in Dutch) of the MIMOS-2 model can be found in Terra-Pilaar (1999).

${ }^{21}$ The calculations account for statutory tax rates, the general tax credit, the general earned-income tax credit, the tax credit and earned-income tax credit for single-parents, the earned-income tax credit for working parents, healthinsurance premiums, housing subsidies, and subsidies to families with dependent children. We also include employees' social-security contributions (SSCs). See Gielen et al. (2009) for a decomposition of the EMTRs by income-dependent taxes and subsidies.

${ }^{22}$ Denote the effective direct marginal tax rate by $t_{d}$, the marginal indirect tax rate by $t_{i}$ and the effective marginal tax rate by $t_{e}$. We calculate the effective total marginal tax rate as $t_{e}=\frac{t_{d}+t_{i}}{1+t_{i}}$.

${ }^{23}$ Own calculations using the input-output tables of Statistics Netherlands (2015).
} 


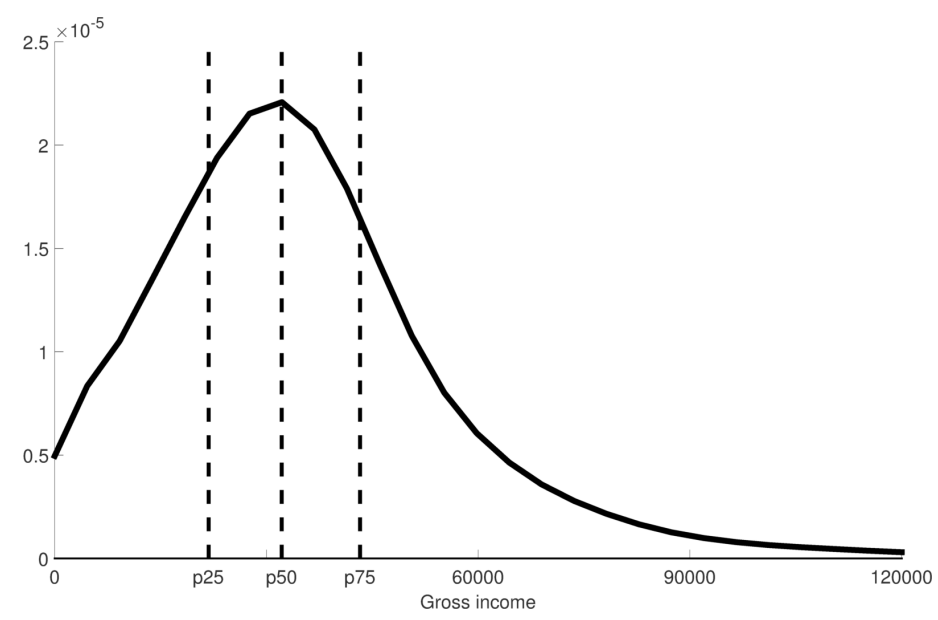

Figure 2: Income distribution in the baseline

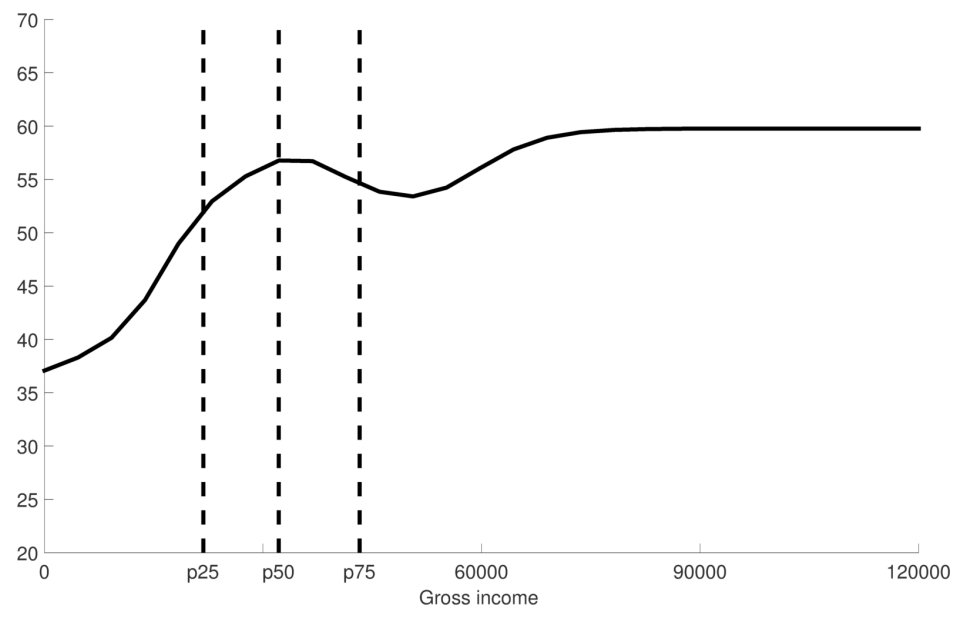

Figure 3: Marginal tax rates in the baseline

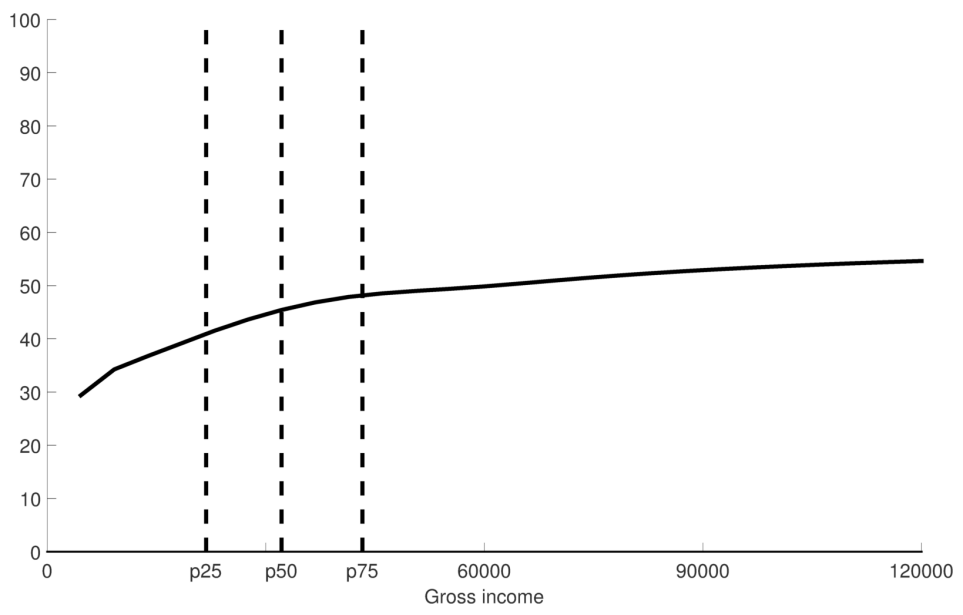

Figure 4: Participation tax rates in the baseline 
stant fraction of consumption, which equals net disposable income in our static setup. Bettendorf and Cnossen (2014) show that this is a good approximation, since consumption of low-VAT and high-VAT commodities are nearly proportional in net disposable income in the Netherlands. ${ }^{24}$

Figure 3 gives a kernel estimate of the resulting EMTRs. We use a kernel estimate to smooth out the variation in individual marginal tax rates at each income level, and across individuals at different income levels. ${ }^{25,26}$ We observe that EMTRs essentially follow the progressive statutory bracket rates, with one major exception. EMTRs are much higher than statutory rates close to the mode of the income distribution (approximately 30 thousand euro), which is where incomedependent subsidies are phased out, in particular rent subsidies and subsidies for families with dependent children.

To determine the PTRs, we first calculate disposable household income when the individual works. Next, we determine disposable household income when the individual does not work. Here, we assume that individuals receive social-assistance benefits when they do not work, provided that there is insufficient income from a potential partner and insufficient household wealth. In doing so we follow official rules of the tax authority and the municipalities. The PTR is then calculated as in Brewer et al. (2010) and OECD (2014): the participation tax rate equals 1 minus the increase in disposable household income as a fraction of gross wage income when the individual moves from non-employment to work. In this way, the PTR accounts for both taxes paid on gross wage income and the loss in social-assistance benefits (if applicable) when exiting non-employment.

Figure 4 gives a kernel estimate of the resulting PTRs. PTRs are lower for low incomes than middle and high incomes. PTRs are relatively low for low incomes because a substantial part of low-income earners are secondary earners. Secondary earners typically do not qualify for social assistance when they do not work because the income of their partner is too high. Also, in the PTRs there is a 'hump' close to the mode of the income distribution, because income-dependent subsidies are phased out.

In the baseline, the government collects 9.5 percent of total labor earnings (i.e., total output) to finance exogenous government consumption. ${ }^{27}$ With the government revenue requirement set at 9.5 percent of total output, the government budget balances under the current tax system with

\footnotetext{
${ }^{24}$ We do not include the tax-deductibility of interest on mortgages and imputed rent on owner-occupied housing. Evidence in Vermeulen and Rouwendaal (2007) suggests that housing supply is nearly completely inelastic in the Netherlands. If housing supply is largely inelastic, then larger demand for housing translates into higher housing prices, and leaves net, after-subsidy housing prices largely unaffected. The tax treatment of housing then has little effect on effective marginal tax rates on labor earnings.

${ }^{25}$ In Appendix D we give a scatter plot of EMTRs showing that there is substantial variation in EMTRs at a given income level for a large part of the income distribution. For a given level of income, EMTRs differ between primary and secondary earners, families with and without children, and between home-owners and tenants.

${ }^{26}$ Jacquet and Lehmann (2015) demonstrate that the Mirrlees (1971) framework can be be generalized to allow for individuals differing in multiple characteristics as long as they make only an earnings-supply choice. Their results carry over to Jacquet et al. (2013) and thus our paper. This implies that all our derivations remain valid, except that we should take averages of all tax rates and elasticities at each income level. Furthermore, as a robustness check we calculate the social welfare weights for different household types and obtain qualitatively similar results.

${ }^{27}$ As government consumption we count expenditures on public administration, police, justice, defense and infrastructure minus non-tax revenues (from e.g. natural gas) as a percentage of GDP, all taken from the Dutch national accounts in Statistics Netherlands (2015).
} 
a social-assistance benefit of approximately 9,400 euro. This is in between the 2006 (disposable) social assistance level of 9,316 euro for singles without children and 15,760 euro for couples with children. In the the baseline, we calibrate the unemployment benefit $b$ and the demogrant $-T(0)$ such that the model-predicted average participation tax equals the observed average participation tax and the government budget constraint holds. ${ }^{28}$

\subsection{Intensive elasticity}

We calibrate the elasticity on the intensive margin by adopting the following utility function: ${ }^{29}$

$$
U=\frac{c^{1-\alpha}}{1-\alpha}-\gamma \frac{(z / n)^{1+\frac{1}{\varepsilon}}}{1+\frac{1}{\varepsilon}}-1(z>0) \varphi, \quad \alpha, \gamma, \varepsilon>0
$$

where $\alpha$ governs the marginal utility of consumption, $\varepsilon$ is the Frisch elasticity of earnings supply on the intensive margin, and $\gamma$ is an innocuous scaling parameter. $z / n=l$ stands for earnings effort. $\varphi$ is the idiosyncratic fixed cost (or benefit) of participation.

The preference parameters $\alpha$ and $\varepsilon$ are calibrated to reproduce the intensive-margin elasticities of the MIMIC model that is used by CPB in the 2002 elections to simulate the long-run employment effects of the reform proposals. ${ }^{30}$ We thus estimate the social welfare weights of political parties based on the same information regarding behavioral responses of taxes as the political parties had in 2002. The income-weighted uncompensated elasticity in our simulations equals 0.2 , which is the employment-weighted average of the uncompensated elasticity in MIMIC across different demographic groups (Graafland et al., 2001, Table 3.2). In addition, we assume that the average income elasticity is -0.05 , which corresponds to the employment-weighted average in MIMIC across different demographic groups. ${ }^{31}$ The estimates for the uncompensated and income elasticities are in line with the estimates surveyed in Blundell and MaCurdy (1999), Evers et al. (2008), and Meghir and Phillips (2010), and with recent estimates of the elasticity of taxable income (ETI) in the international literature and in the Netherlands, see Saez et al. (2012) and Jongen and Stoel (2013).

\subsection{Distribution participation costs}

Finally, the distribution of participation costs $h(\varphi)$ determines the participation elasticity in our model. We target an average participation elasticity $\zeta^{T}$ of 0.16 in the simulations, based on

\footnotetext{
${ }^{28}$ Appendix D provides a comparison of the model-predicted participation taxes and the observed participation taxes by income levels.

${ }^{29}$ This utility function is also used by Mankiw et al. (2009). When $\alpha \rightarrow 1$ this utility function converges to the logarithmic Utility Type-II used by Saez (2001). When $\alpha=\frac{1}{\varepsilon}$ this specification is in line with the CES-functions used by Mirrlees (1971) and Tuomala (1984).

${ }^{30}$ See Graafland et al. (2001) for a description of the MIMIC model, the calibration and a large number of simulations.

${ }^{31}$ The uncompensated intensive elasticity for primary earners (in couples), secondary earners, singles (without children), single parents and 'older' workers (55-64 years of age, treated as a separate group) is $0.1,0.25,0.25,0.5$ and 0.15 , respectively. The income elasticities for the same demographic groups are assumed to be $0.0,-0.2,-0.05$, -0.1 and 0.0, respectively (Graafland et al., 2001, pp.76-78).
} 
Graafland et al. (2001, Table 10.1, Columns 1-3) who find that the aggregate participation response is about 80 percent of the aggregate intensive-margin response (0.20). Furthermore, we target the extensive-margin elasticity by income quartiles. ${ }^{32}$ Mastrogiacomo et al. (2015) estimate extensive-margin elasticities by income quartile for singles, single parents, men in couples (typically primary earners) and women in couples (typically secondary earners) using Dutch data for the period 1999-2005. We use the population weights of these groups in MIMIC to calculate a weighted average extensive-margin elasticity by income quartile, where we normalize the elasticities such that the average extensive-margin elasticity across income quartiles is in line with MIMIC. ${ }^{33}$

The distribution of participation costs $h(\varphi)$ is assumed to follow a non-standardized $t$-distribution with mean $\mu$, scale-parameter $\sigma$, and degrees of freedom $\nu{ }^{34}$ We estimate $h(\varphi)$ with a non-linear least-squares regression using data on the participation or extensive-margin elasticities and using data on education-specific employment rates. ${ }^{35}$ Further, under the assumption that the cumulative distributions of education and ability are the same, we can obtain 5 ability-specific employment rates. In total we have 9 data points to estimate the parameters of $h(\varphi)$. See Appendix C for more details on the estimation procedure.

\section{Proposals political parties}

We focus on the four largest political parties in the Dutch parliament after the 2002 elections that fit into the 'left-wing' and 'right-wing' taxonomy regarding political preferences for redistribution: the left-wing Socialist Party (SP), the center-left Labour Party (PvdA), the center-right Christian-Democratic Appeal (CDA) and the right-wing People's Party for Freedom and Democracy (VVD). ${ }^{36,37}$

Changes in the tax-benefit system result in changes in the EMTRs and PTRs for each political party. Since the changes in tax rates are the main drivers of the changes in social welfare weights we plot the EMTRs for each party and discuss the changes in PTRs. Our calculations of changes in EMTRs take into account proposed changes in indirect taxes and corporate taxes. Indirect taxes

\footnotetext{
${ }^{32}$ These are not reported in Graafland et al. (2001), therefore we use the extensive-margin elasticities reported in Mastrogiacomo et al. (2015).

${ }^{33}$ The participation elasticity is different for tax and benefit changes. The participation elasticity $\zeta^{T}$ is the participation elasticity with respect to the participation tax rate when income taxes change. The participation elasticity with respect to the participation tax rate when benefits change equals $\zeta^{b}=v^{\prime}(b) / u_{c} \zeta^{T}$.

${ }^{34}$ When the degrees of freedom converge to infinity, the distribution converges to a normal distribution with mean $\mu$ and standard deviation $\sigma$. Due to the extra parameter the non-central $t$-distribution allows us to obtain a better fit of employment rates and elasticities than with the normal distribution.

${ }^{35}$ We calibrate the employment rates by level of education to the data from the Dutch Labor Force Survey (Statistics Netherlands, 2006), see Appendix C.

${ }^{36}$ We do not consider the populist party of Pim Fortuyn, because they did not submit a tax-benefit plan to CPB in the 2002 elections.

${ }^{37}$ Appendix $\mathrm{F}$ gives a brief introduction to the Dutch political system and the Dutch political parties that participated in the 2002 elections. CPB (2002b) gives an extensive overview of the proposed policy changes and the resulting effects in Dutch. Appendix G contains the detailed list of proposals for the tax-benefit system. Clearly, the proposals of the political parties are not confined to the tax-benefit system. A brief English summary of the full analysis of the election proposals can be found in CPB (2002a). Furthermore, Graafland and Ros (2003) consider the pros and cons of this unique Dutch exercise, which was conducted first in the run up to the 1986 elections.
} 


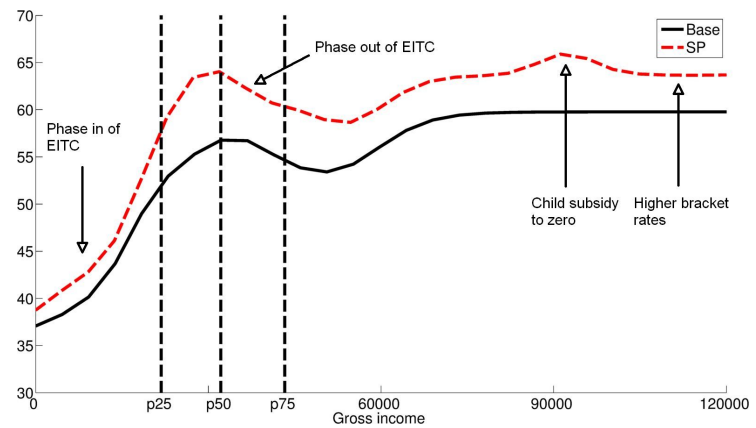

(a) Socialist Party (SP)

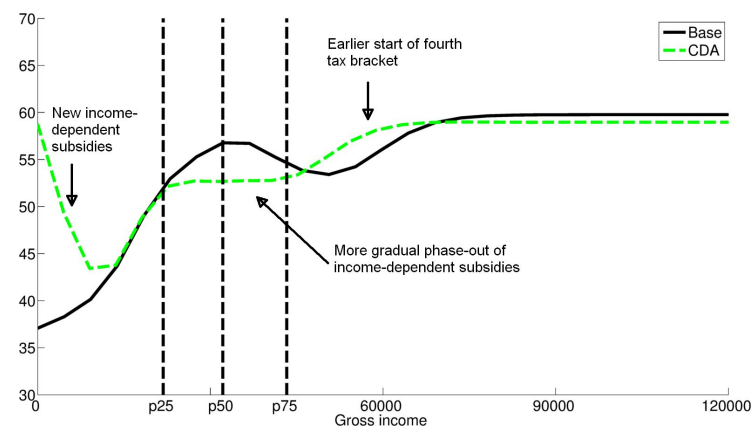

(c) Christian-Democratic Appeal (CDA)

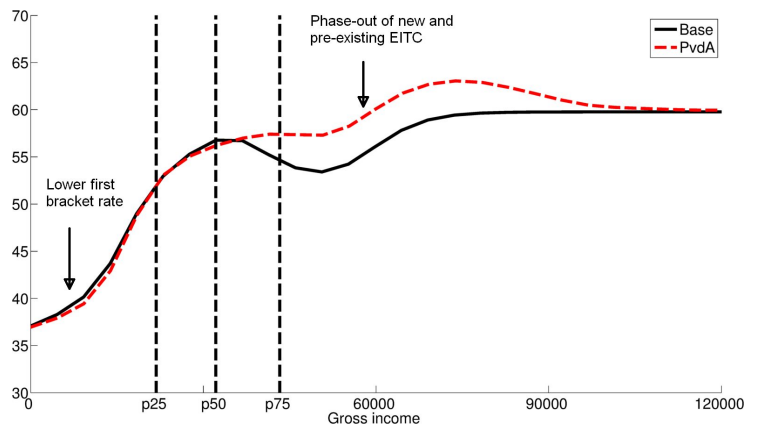

(b) Labor Party (PvdA)

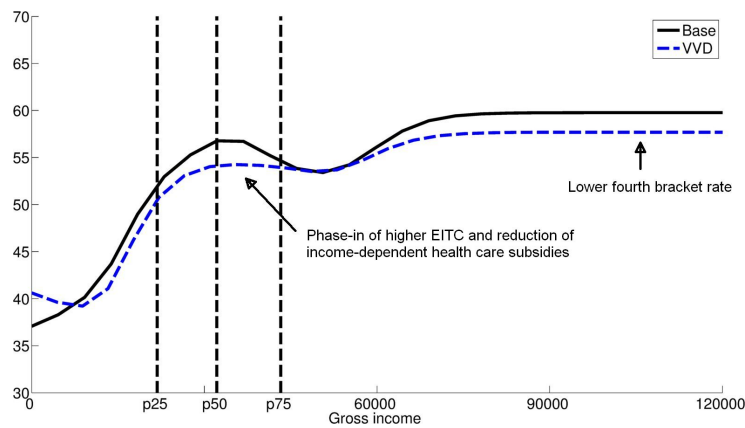

(d) People's Party for Freedom and Democr. (VVD)

Figure 5: Effective marginal tax rates by income of proposals political parties

are assumed to be proportional in net income, like in the baseline. We assume that all changes in business taxes are fully shifted onto workers, which is not unreasonable given that the Netherlands is a small open economy and capital mobility is very high. ${ }^{38}$ Specifically, the change in the EMTR due to a corporate tax change equals the percentage change in (ex ante) corporate tax revenue as a fraction of the wage bill. We do not account for the changes in taxes on capital income or wealth, since the Netherlands has a dual tax system where labor and capital incomes are taxed separately and our focus is on the taxation of labor income. ${ }^{39}$ Appendix $\mathrm{G}$ provides an exhaustive list of all tax and benefit measures taken by each political party and provides the scatterplots of EMTRs on which our kernel estimates are based. This section only highlights the main changes proposed by each political party.

We first consider the proposed changes by the left-wing Socialist Party (SP). Figure 5 (panel a) plots the resulting kernel of EMTRs for the SP in comparison to the baseline. The SP raises EMTRs across the board due to higher marginal tax rates on labor income, higher indirect taxes, and higher corporate taxes. The SP abolishes health-care premiums, which is financed by an increase in the

\footnotetext{
${ }^{38}$ The extent to which business taxes are borne by firms, workers and consumers is discussed in the public finance literature (Fuchs et al., 1998; Mooij, 2005). A recent meta-analysis Melguizo and González-Páramo (2013) suggests that workers bear 74 percent of employers' social-security contributions. Jacobs (2015) estimates that more than 90 percent of employer taxes are borne by workers in the Netherlands.

${ }^{39}$ Also CPB (2002b) ignored the effects of changes in capital taxes on the labor market outcomes and the income distribution.
} 
first bracket rate with 2.3 percentage points, and an increase in the second, third and fourth bracket rates by 3 percentage points. ${ }^{40}$ The SP also proposes a fifth, top bracket with a rate of 72 precent for gross incomes above 213,358 euro. This is not visible, since we only plot incomes up to 120 thousand euro. The SP further introduces an additional earned-income tax credit (EITC). This EITC is phased in between 100 and 130 percent of the annual minimum wage of 16,484 euro in 2006. It reaches a maximum of 1,017 euro. It is completely phased out between 130 percent and 170 percent of the minimum wage. The phase-in of the EITC limits the rise in marginal tax rates at the bottom, but significantly raises marginal tax rates in the phase-out range, around 25 thousand euro. The SP raises the (lump-sum) general child subsidy for lower incomes, cuts it in half at 45,000 euro, and completely withdraws it at 90,000 euro. Marginal tax rates increase at these income thresholds. The SP raises social-assistance benefits by 5 percent. Furthermore, they introduce a tax credit for non-workers which raises benefits for the non-employed by another 3 percent.

Next, consider the tax-benefit reforms proposed by the center-left Labor Party (PvdA), see also Figure 5 (panel b). Marginal tax rates increase for the upper-middle and top incomes, which is due to changing the pre-existing EITC and introducing a new, additional EITC. The PvdA proposes to phase out the EITC - which is not phased out in the baseline tax system - between 240 and 400 percent of the minimum wage. The additional EITC features a phase-in range between 90 and 100 percent of the minimum wage, where it reaches a maximum of 353 euro, and is phased-out between 180 and 240 percent of the minimum wage. The PvdA also reforms the financing of health insurance, but this hardly affects the EMTRs. Finally, the PvdA raises indirect taxes, but reduces corporate taxation at the same time. These changes roughly cancel out.

Figure 5 (panel c) gives the resulting kernel of EMTRs for the center-right Christian-democratic party (CDA). The most notable change is the rise in the marginal tax burden at the lower end of the income scale due to targeting income support more at low-income families by introducing incomedependent subsidies for health-care costs and for children, and by raising housing subsidies. The CDA-proposals also result in a more gradual phase-out of the overall system of income-dependent subsidies for housing and dependent children. This results in a noticeable drop in EMTRs around the mode of the income distribution. Furthermore, the earlier start of the fourth tax bracket raises EMTRs beyond the middle incomes. The CDA lowers the starting point of the fourth tax bracket by 4,440 euro, which effectively raises marginal tax rates over this income range. The CDA increases the pre-existing EITC with 72 euro. The CDA reforms the financing of health insurance, but this hardly affects the EMTRs. The CDA increases the refundable tax credit for non-working partners. Furthermore, the CDA reduces corporate taxes by lowering employers' social-security contributions and leaves indirect taxes virtually unchanged.

Finally, we consider the proposals by the right-wing conservative-liberal party (VVD), see Figure 5 (panel d). Most notable are the reductions in EMTRs for the middle- and top-income groups.

\footnotetext{
${ }^{40}$ This shift from health-care premiums to bracket rates raises EMTRs for middle and higher incomes. In the baseline, health care premiums rise up to an income of approximately 30 thousand euro, for incomes beyond 30 thousand euro they are income independent, see Gielen et al. (2009).
} 
The VVD phases out income-dependent subsidies and tax credits more slowly with income and it reduces the fourth bracket (top) rate by 3 percentage points. EMTRs are lower than in the baseline around the mode because the VVD increases the EITC (by 232 euro) and because the VVD converts the income-dependent health-care premiums to a lump-sum amount. Furthermore, the VVD does not phase the EITC out, contrary to the left-wing parties SP and PvdA. The VVD leaves benefits for non-workers virtually unchanged, and increases indirect and corporate taxes somewhat. The VVD abolishes employer subsidies targeted at low-wage workers and abolishes the exemption of corporate taxation for pension funds.

\section{Social welfare weights}

\subsection{Baseline welfare weights}

Figure 6 gives the social welfare weights in the baseline. We observe that these social welfare weights are only roughly in line with a standard social welfare function featuring gradually diminishing social welfare weights. Indeed, although social welfare weights are generally higher for low- than for highincome individuals, they are not monotonically declining in income and they are not positive for all income levels. The social welfare weight for the non-employed is only slightly higher than that of the working poor. This means that the government values redistribution towards these groups roughly equally.

Striking is the anomaly that the social welfare weights rise with income until the mode of the earnings distribution. ${ }^{41}$ As explained in the theory section, this is a direct result of rising marginal tax rates in the lower part of the income distribution. This pattern of marginal tax rates can be optimal only when the government attaches a higher social welfare weight to the middle-income groups than to the low-income groups. This anomaly means that the government redistributes 'too much' to middle incomes, as long as a marginal euro is worth more to the poor than to the middleincome groups. Also, higher up the income distribution, close to 60,000 euro, welfare weights rise with income, because of the drop and subsequent rise in marginal tax rates around 60,000 euro. Apparently, the government values an extra euro for individuals with an income of 60,000 euro a bit more than an extra euro for individuals with a somewhat lower income.

A second anomaly is that top-income earners get a negative social welfare weight, since the top tax rate is set beyond the Laffer rate which maximizes tax revenue. ${ }^{42}$ A plausible explanation is that $\mathrm{CPB}$ only reported the effects on the government budget of proposed policy changes excluding behavioral responses, but the behavioral responses are the reason why a higher top tax rate leads to a deterioration of the government budget.

Proposition 2 in the theory section derived that there are four factors that explain the behavior of social welfare weights with income. Figure 6 decomposes the social welfare weights into the

\footnotetext{
${ }^{41}$ This finding is in line with the findings of related studies on other countries. Bourguignon and Spadaro (2012) find relatively low social welfare weights for the working poor in France and Bargain et al. (2014) find it for a number of European countries.

${ }^{42}$ Bourguignon and Spadaro (2012) also find negative social welfare weights for top-income earners in France.
} 


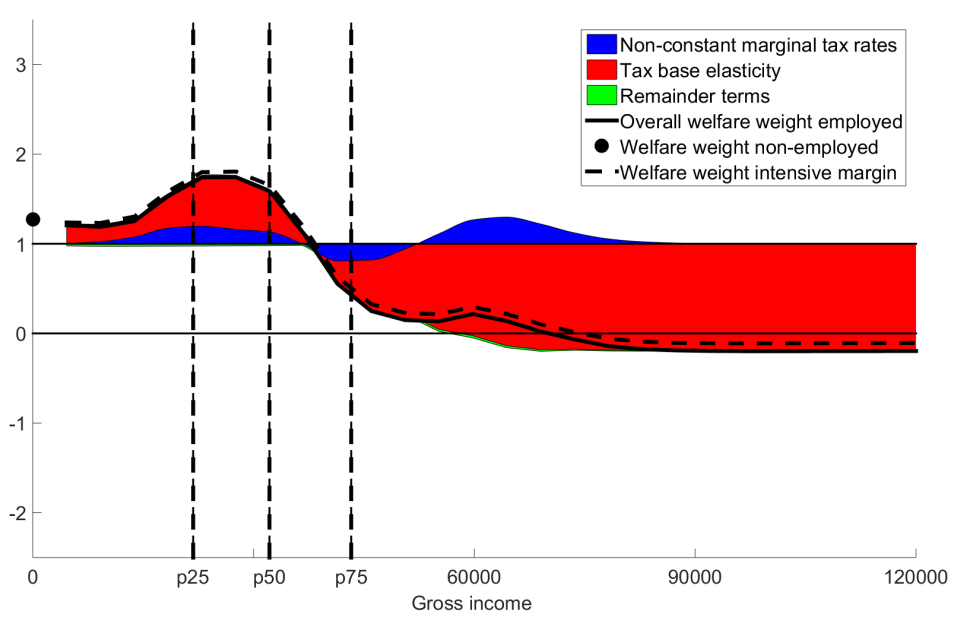

Figure 6: Social welfare weights in the baseline

contribution of these four factors: the tax-base elasticity, non-constant marginal tax rates, and the remaining terms: non-constant intensive elasticities, income effects and participation effects. The red part in Figure 6 reveals that the most important driver of the social welfare weights is the elasticity of the tax base $\theta_{z}$ with income: does the tax base increase or decrease when earnings increase? Also, changes in marginal tax rates matter as indicated by the blue part, but to a much lesser degree. This would be different, however, if the tax schedule would feature a U-shape. The baseline marginal tax schedule does not feature spikes, hence these are not very important. Income effects, participation responses and non-constant intensive elasticities have a minor quantitative effect on social welfare weights as indicated by the green part.

The dotted line in Figure 6 shows that the social welfare weights are nearly the same when the extensive margin is switched off completely. Our findings thus imply that results from earlier studies that ignored income effects and participation responses give a good approximation.

How robust are our anomalies? We can think of two potential economic explanations for increasing social welfare weights with income at the bottom of the income distribution. First, our model ignores differences in the labor-supply elasticity of primary and secondary earners. Secondary earners have a (much) higher labor-supply elasticity than primary earners, see for recent Dutch estimates Jongen and Stoel (2013) and Jongen et al. (2014). If we assume elasticities that are too low for low-income earners, we underestimate the social welfare weights at low incomes, see also the theory section. Second, the earnings distribution determines the efficiency costs of taxation. If different household types have both different elasticities and different earnings distributions, then the bias in our findings could potentially be attenuated. Indeed, in the Netherlands many secondary earners can be found at the lower end of the earnings distribution due to the high incidence of part-time work. ${ }^{43}$ We check whether these two concerns are important.

\footnotetext{
${ }^{43}$ Our model also ignores intra-household redistribution, among other things. This may lead us to overestimate the social welfare weights for the low-income earners, since secondary earners with low incomes receive transfers from primary earners, and under-estimate the welfare weights for top income earners, since they transfer income to their partners. This is not something we can fix, since we lack the information on intra-household transfers and there is
} 


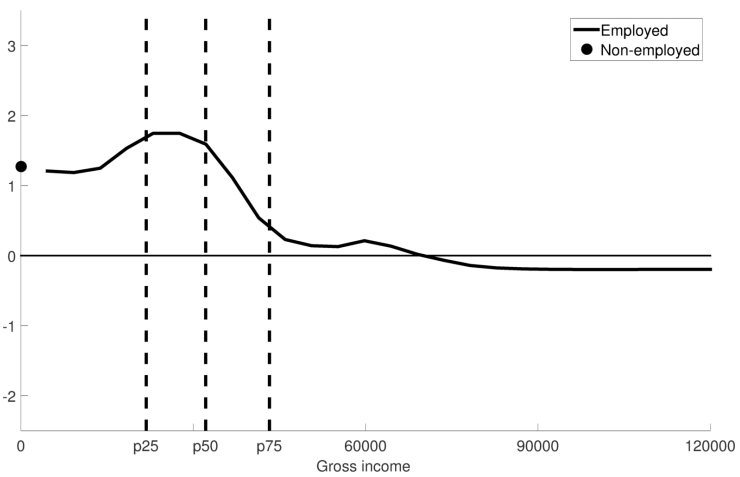

(a) Baseline

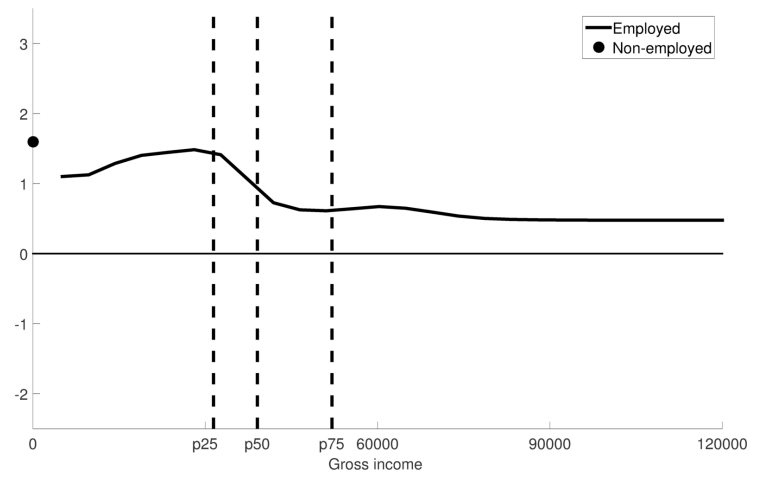

(c) Primary earners

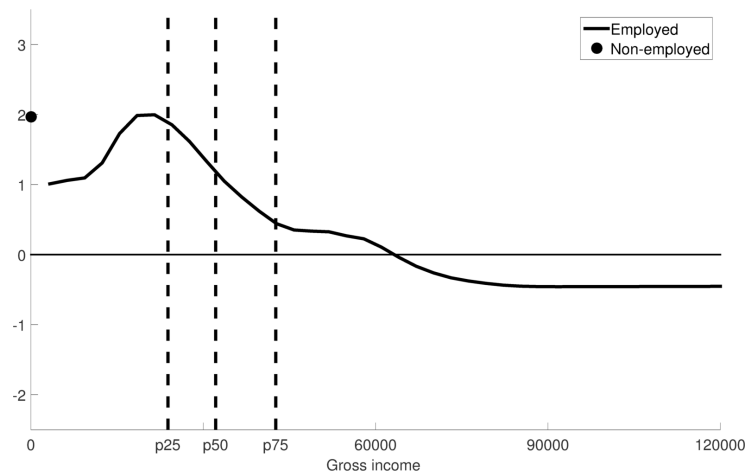

(b) Singles

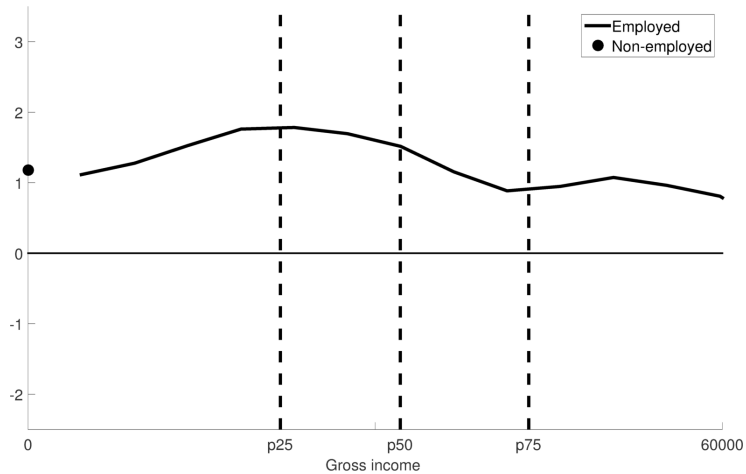

(d) Secondary earners

Figure 7: Social welfare weights for different household types

First, we check whether the patterns in social welfare weights are driven by differences in household types and differences in their elasticities. For each household type we employ their specific income distributions, EMTRs and PTRs, and extensive- and intensive-margin elasticities. Figure 7 shows that the first anomaly - increasing social welfare weights towards the mode - is robust. Social welfare weights are still increasing up to the mode for singles, primary earners (which we approximate by men in couples) and secondary earners (which we approximate by women in couples). Moreover, the second anomaly - negative welfare weights for the rich - is preserved for all groups except for primary earners, because of their much lower intensive elasticity. ${ }^{44,45}$

Second, we check how sensitive our findings are with respect to the presumed elasticities on the intensive and extensive margins. The graphs for the social welfare weights in the next section reveal that the two anomalies are exacerbated when we assume more elastic responses. However, when we assume lower extensive and intensive margin responses, only the first anomaly is preserved; social

not yet an inverse optimal-tax method for families. See the small literature looking at family taxation, e.g., Boskin and Sheshinski (1983), Apps and Rees (1998), Schroyen (2003), Kleven et al. (2009) and Alesina et al. (2011).

${ }^{44}$ The social welfare weights also remain positive at the top for women in couples, but there are only very few observations for which this is relevant.

${ }^{45}$ Also, when we do not explicitly distinguish between the extensive and intensive margin, as in Mirrlees (1971), the anomalies remain, see Figure 6. In the MIMIC model, which we emulate in the calibration, the intensive-margin response is relatively important compared to the extensive-margin response. 


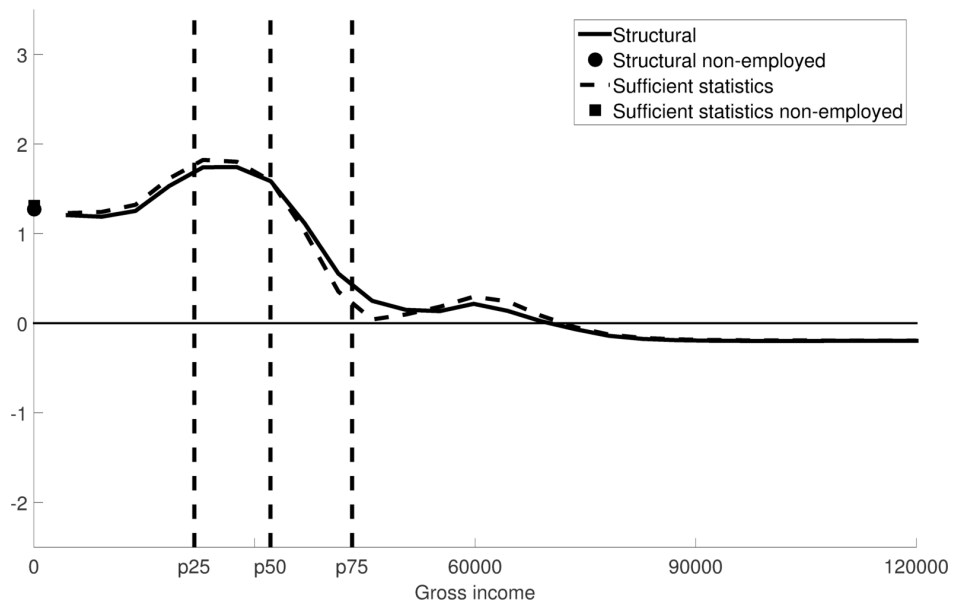

Figure 8: Social welfare weights: sufficient statistics versus structural approach

welfare weights are still increasing up to the middle incomes. The second anomaly is not robust, since the social welfare weights for the top incomes become positive under low elasticities on the intensive margin.

As a third robustness check, we also verify whether our results could be sensitive to redistribution via transfers in kind. When the benefits from in-kind transfers differ across income groups, the EMTRs are affected, and our calculations of the social welfare weights could be biased. Our calculations above already included the distributional impact of health-care system and rent-assistance. Kuhry and Pommer (2006) provide estimates of the use of other in-kind transfers by deciles of net disposable household income, such as public transportation, museums, culture and arts, sport facilities, parks and other recreational goods. Using these data, Appendix E shows that including in-kind transfers has only a small impact on EMTRs. The changes in EMTRs range between -2.2 and +3.5 percent of disposable household income. It is not feasible to adjust our baseline EMTRs for the redistributive component of in-kind transfers, and recalculate the social welfare weights, since we cannot map the changes in EMTRs in terms of disposable household income into changes in EMTRs in terms of individual gross earnings. Nevertheless, since the EMTRs based on disposable household income change very little, accounting for the redistributional component of in-kind transfers will have only a small effect on estimated social welfare weights.

As a final robustness check we compare the welfare weights from the structural model with the welfare weights using sufficient statistics. Figure 8 plots the social welfare weights derived under both approaches. We see that the structural model and the sufficient statistics give very similar social welfare weights. This implies that misspecification of the structural model is not likely to bias our findings. Moreover, this also implies that - as long as tax changes remain small - one can forego calibrating a complicated structural model, and derive the social welfare weights of any tax-benefit system using sufficient statistics only: information on tax rates, elasticities, and the earnings distribution. 


\subsection{Welfare weights political parties}

Figure 9 reveals the political preference for income redistribution by political party. Each panel compares the social welfare weights of each party and compares them to the welfare weights from the pre-existing tax-benefit system. ${ }^{46}$ As expected, all parties roughly attach higher weights to the poor than to the rich. The left-wing parties SP and PvdA attach a relatively higher welfare weight to the poor than the right-wing parties CDA and VVD do. The reverse applies to the high-income earners. The SP is the only party that proposes to raise benefits for the non-employed, which increases the social welfare weight for the non-employed.

The SP exacerbates the first anomaly in the baseline by raising the social welfare weight on incomes close to the middle-income groups even further relative to the 'working poor'. This is the result of the phase-out of the EITC just above the minimum wage. The proposals of the PvdA do not exacerbate the first anomaly, but they do not reduce it either. The proposals of the SP and PvdA both exacerbate the second anomaly - that social welfare weights are negative at the top by pushing the top rate further beyond the Laffer rate. Note that the graph excludes individuals earning more than 213,358 euro, who face a 72 percent top rate in the SP proposals. For the PvdA it is also surprising that they attach a higher social welfare weight to the 'very rich' (beyond 100,000 euro) than to the 'rich' (between 70,000 and 100,000 euro). This is the result of the phase-out of the EITC programs. For the SP we see a sudden rise and drop in the social welfare weights for incomes close to 90,000 euro, which is due to the withdrawal of the child subsidy at that income level. This finding suggests that the SP cares much more about families with children somewhat below 90,000 euro than somewhat above 90,000 euro.

The proposals of the right-wing parties CDA and VVD do not exacerbate, but reduce the preexisting anomaly of giving a higher welfare weight to middle-incomes than to the working poor. Especially the CDA reduces the social welfare weights on the middle-income groups, which is due to the stronger phase out income-dependent programs for rent, children and health care. The VVD also slightly reduces the first anomaly, but the effects are less pronounced than for the CDA. However, the VVD more strongly alleviates the second anomaly - negative social welfare weights for the rich - because it reduces the top rate of the income tax.

The most striking finding or our analysis is that all political parties attach the highest social welfare weight to middle incomes. Moreover, political parties barely change the pre-existing taxbenefit system. Consequently, the social welfare weights of the different political parties hardly deviate from those in the pre-existing tax-benefit system. Dutch redistributive politics features a strong status quo, which sustains and benefits the position of middle-income groups. Below we provide a number of political explanations for this finding.

We check the robustness of our findings using different assumptions regarding the behavioral responses. In Figures 10 and 11 we plot the social welfare weights for all political parties when we increase or decrease the elasticities with 50 percent. ${ }^{47}$ The first anomaly is robust to changes in

\footnotetext{
${ }^{46}$ Appendix $\mathrm{H}$ also provides the decomposition of the social welfare weights for each party into its main determinants.

${ }^{47}$ In the high-elasticity scenario we raise the compensated (uncompensated) elasticity to 0.38 (0.30), the income
} 


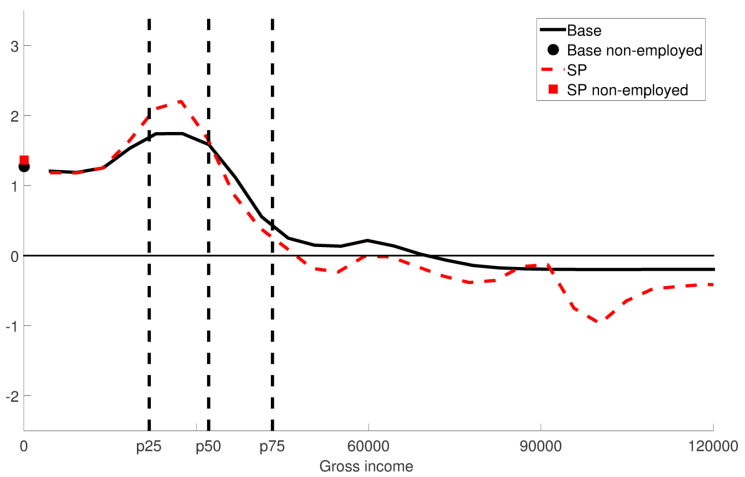

(a) Socialist Party $(\mathrm{SP})$

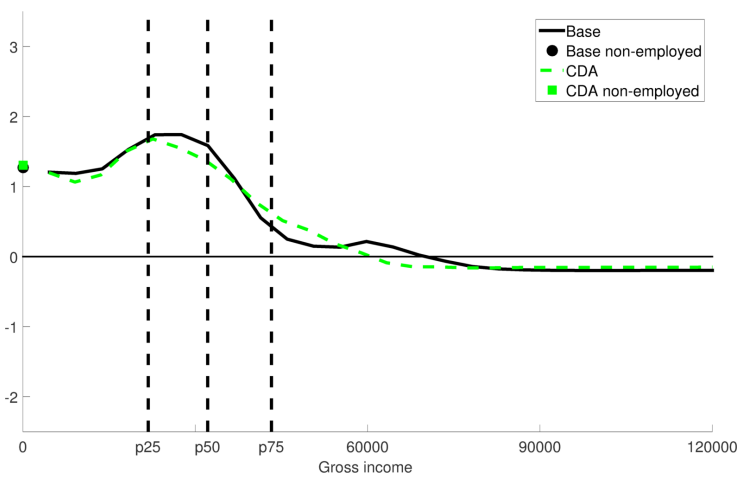

(c) Christian-Democratic Appeal (CDA)

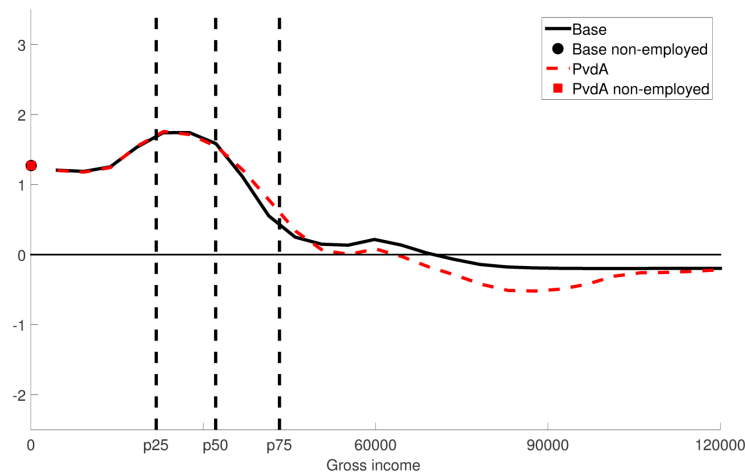

(b) Labor Party (PvdA)

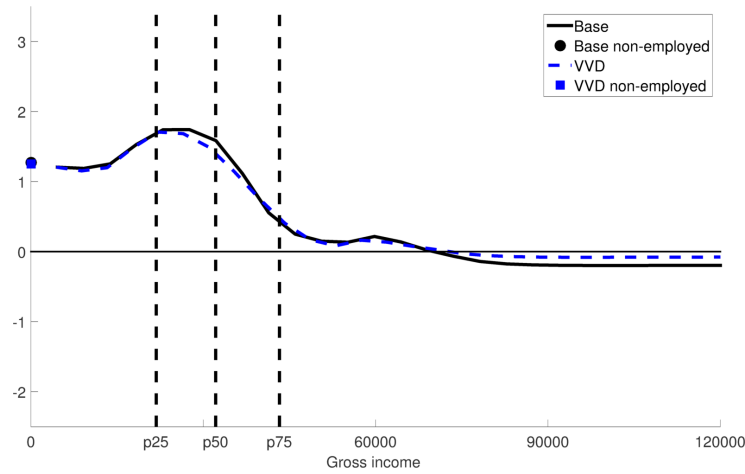

(d) People's Party for Freedom and Democr. (VVD)

Figure 9: Social welfare weights political parties

the elasticities, although the patterns in social welfare weights become less pronounced when we assume low elasticities. The second anomaly is preserved only under the high-elasticity scenario and disappears in the low-elasticity scenario. The status quo bias becomes stronger (weaker) when we assume smaller (larger) extensive and intensive elasticities. However, the similarities across parties remain more striking than their differences.

Our results contrast sharply with the heated political rhetoric during the elections. Indeed, political parties strongly profile themselves as caring more about the poor (SP) or the rich (VVD) and make promises that things will be very different once they are elected. However, we find that all parties mainly serve the large group of middle-income voters. Furthermore, there appears to be a strong status-quo bias in the proposals of Dutch political parties, since their proposals hardly change the net income distribution.

elasticity to 0.08 , and the participation elasticity to 0.23 . In the low elasticity scenario we lower the compensated (uncompensated) elasticity to $0.13(0.10)$, the income elasticity to 0.03 , and the participation elasticity to 0.08 . 


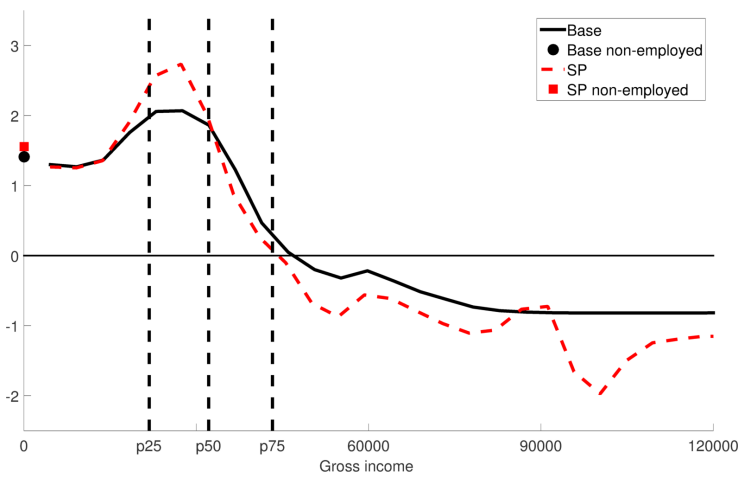

(a) Socialist Party (SP)

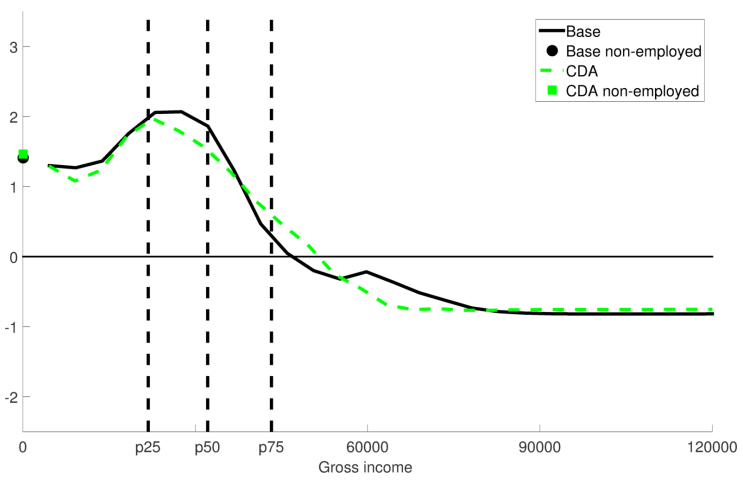

(c) Christian-Democratic Appeal (CDA)

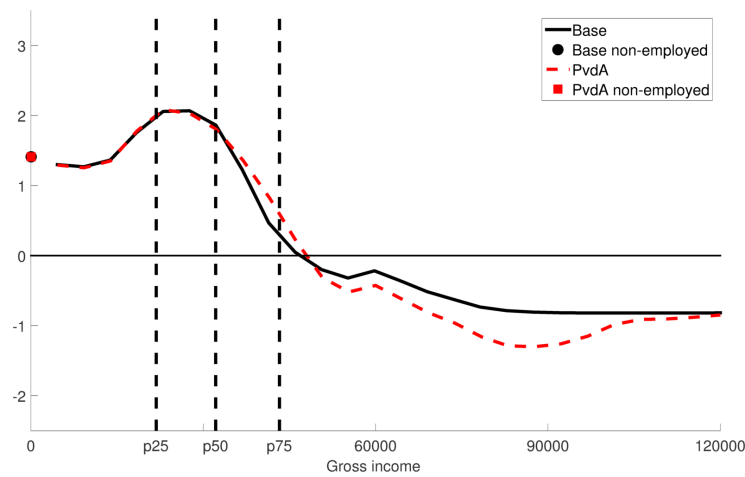

(b) Labor Party (PvdA)

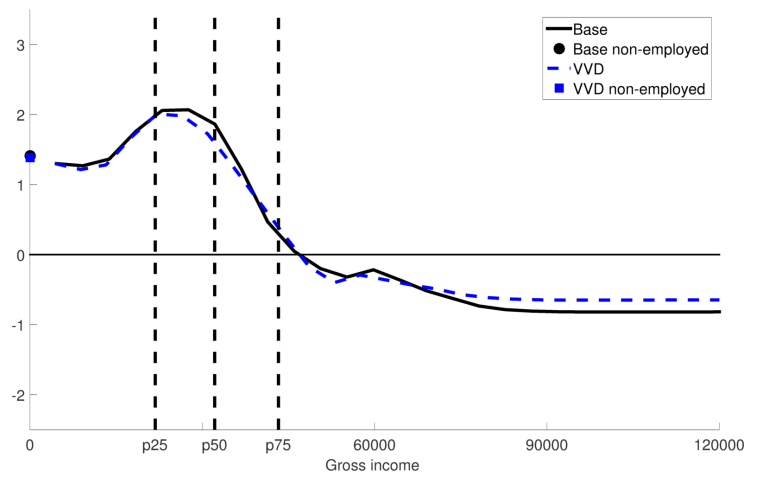

(d) People's Party for Freedom and Democr. (VVD)

Figure 10: Social welfare weights with higher elasticities of the tax base and participation

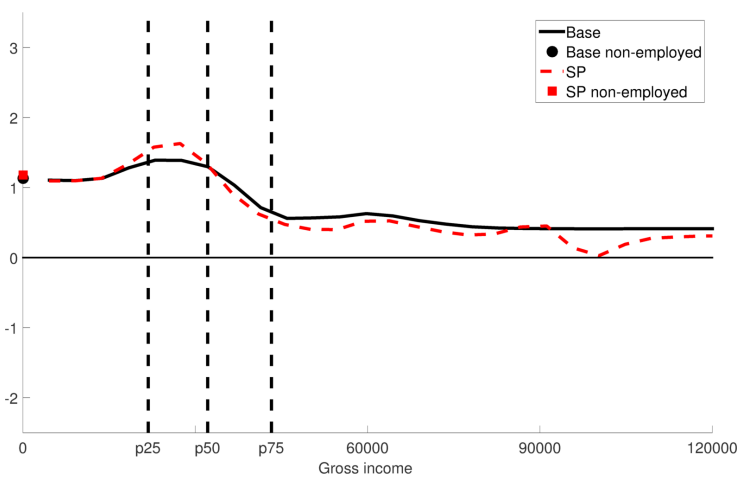

(a) Socialist Party (SP)

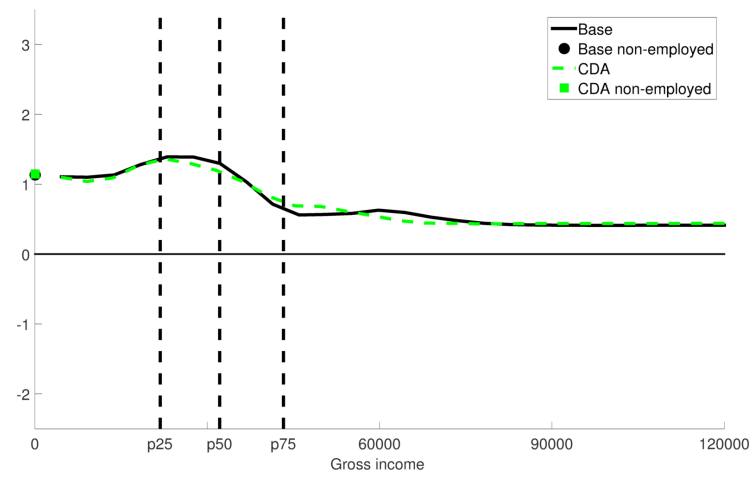

(c) Christian-Democratic Appeal (CDA)

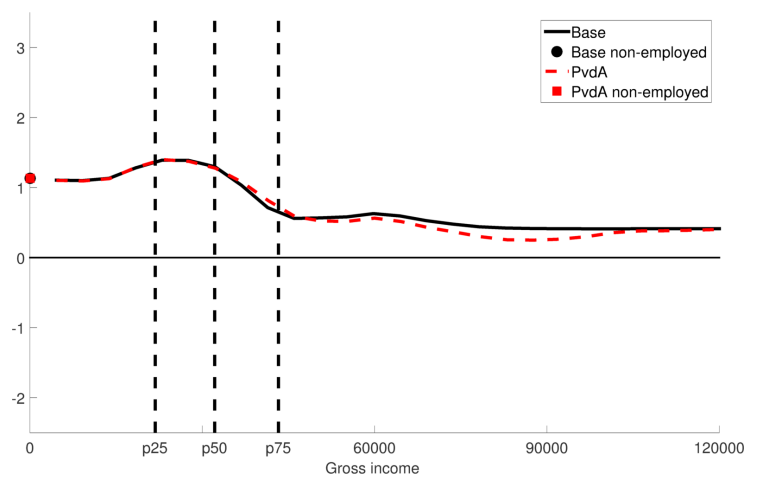

(b) Labor Party (PvdA)

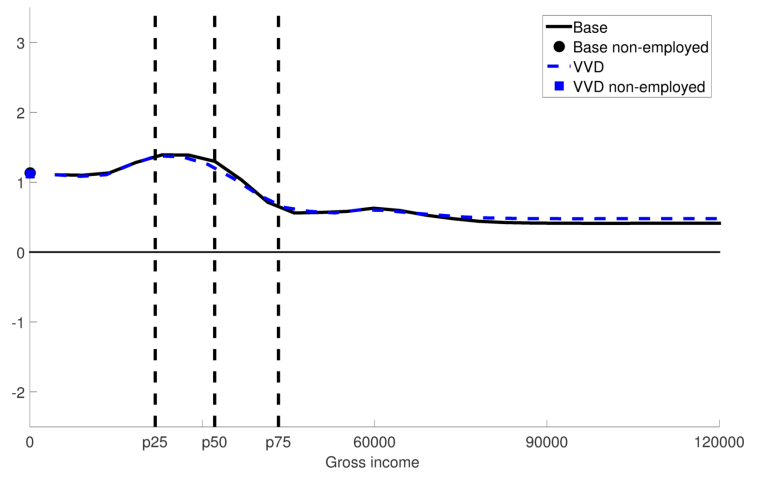

(d) People's Party for Freedom and Democr. (VVD)

Fioure 11: Social welfare weichts with lower elasticities of the tax base and particination 


\section{Discussion}

Our analysis reveals one important and robust anomaly in the redistributive preferences of the existing government and in the proposals of the political parties: social welfare weights are increasing until modal income. Moreover, social welfare weights are negative for top-income earners, although this latter finding is dependent on the elasticity of taxable income. Both findings imply that the existing government and all Dutch political parties like to raise income redistribution towards the middle class at the expense of both the low-income and high-income groups. Moreover, the social welfare weights look remarkably similar across parties and compared to the welfare weights of the pre-existing tax-benefit system. This heavy status-quo bias suggests that our findings are deeply rooted in Dutch redistributive politics. Our findings beg the question whether there are political reasons that can rationalize these findings. And, indeed, our findings bolster some theories that feature prominently in the literature on political economics.

First, the rise in social welfare weights from the working poor to the middle-income groups and the subsequent sharp drop in these weights thereafter can be understood by standard political models of income redistribution. Romer (1975), Roberts (1977), and Meltzer and Richard (1981) develop median-voter models of income redistribution through linear taxation. These models explain why income redistribution is geared towards the median voter. Although the tax-benefit system in the Netherlands is determined by coalition governments, and not by the median voter, these political-economy models are intuitively appealing. In countries with coalition governments, political parties have to attract enough votes from the densely populated middle-income groups as well.

Röell (2012) and Brett and Weymark (2014) generalize these models to the political economy of non-linear income taxation using citizen-candidate models. These authors derive that preferences over non-linear tax schedules are single peaked. Hence, a majority-voting equilibrium can be derived. Brett and Weymark (2014) demonstrate that the median citizen candidate soaks both the low-income and the high-income groups by setting a maxi-min tax schedule for the individuals above her and maxi-max tax schedules for individuals below her. This is also exactly what we find empirically. The patterns of the social welfare weights - increasing to modal incomes and decreasing thereafter - are also consistent with Director's law (Stigler, 1970), according to which the middle-income groups can form a successful, stable political coalition to extract resources from both the low-income and the high-income groups, because the latter groups cannot align their political interests very well.

Second, probabilistic voting models could explain why left-wing parties sacrifice on their preference to redistribute income so as to gain voters on other, ideological positions, see also Persson and Tabellini (2000) and Bierbrauer and Boyer (2016). Alternatively, Roemer (1998, 1999) shows that the poor - having a larger electorate - may not want to soak the rich through redistributive tax systems. He develops models of two-dimensional political competition where political parties position themselves on their redistributive preference and some non-economic ideological preference, such as religion. Even left-wing parties may then sacrifice on their redistributive goals if this 
helps to achieve larger electoral success by attracting more voters on their non-economic, ideological position.

Third, post-election considerations could explain the large status-quo bias that we observe in our analysis. Indeed, political parties may not want to deviate too much from the status quo given that they need to form a coalition government with other political parties after elections are held. Coalition agreements are more difficult to achieve if there has been a polarized political campaign based on sharp ideological differences. See also Persson and Tabellini (2000).

Fourth, the strong status-quo bias and the highest welfare weights for the middle-income groups could also be explained by collective-action problems. Welfare-improving reforms of the tax-benefit system - provided that welfare weights should decrease with income - impose costs on the densely populated middle groups, while the benefits acrue to the electorate at large. Vested interests among the middle-income groups could, therefore, be effective in blocking welfare-improving tax-benefit reforms. See also Olson (1982).

\section{Conclusions}

In this paper we have used the inverse optimal-tax method to reveal the redistributive preferences of Dutch political parties. We exploit unique data on the proposed tax-benefit system of Dutch political parties in their election programs. We contribute to the existing literature by deriving the social welfare weights in the optimal-tax model of Jacquet et al. (2013), which incorporates both intensive and extensive labor-supply margins.

Only part of our findings confirm prior expectations. First, all political parties roughly give a higher social welfare weight to the poor than to the rich. Second, left-wing parties generally give a higher social welfare weight to the poor and a lower social welfare weight to the rich than right-wing parties do. We uncover two important anomalies. Social welfare weights are found to be increasing from the working poor to the middle class, which implies that Dutch political parties prefer reverse redistribution from the poor to the middle class. This anomaly is robust. Second, the social welfare weight of the rich is slightly negative, hence Dutch political parties want to "soak the rich' completely, and they try to do even more than that. However, this finding is sensitive to the elasticity of taxable income for top-income earners.

We show that both anomalies are preserved by all Dutch political parties in their election programs. The left-wing parties, however, increase the welfare weight of the middle class even further and reduce the welfare weight of the top-income earners even more below zero. The rightwing parties do the reverse: they reduce the welfare weights of the middle classes, while raising the welfare weight for the top-income earners. A striking finding is the extreme similarity across political parties of the social welfare weights. Dutch political preferences for income redistribution are therefore deeply rooted in a political status quo. We argue that political-economy considerations are important to explain the political preferences of income redistribution in the Netherlands. Dutch redistributive politics strongly favors the middle class at the expense of both the poor and the rich 
income groups. Hence, Dutch redistributive politics seems to be determined by the 'tyranny' of the majority, the middle class.

Finally, we have some directions for future research. Our sufficient-statistics approach foregoes the need to develop complex structural models and can be readily applied to estimate social welfare weights for other countries and time periods using information only on tax rates, income distributions, and behavioral elasticities. ${ }^{48}$ Moreover, our analysis rests on the assumption that political parties act in their best political interest by maximizing a clearly defined political objective function. Political parties have all kinds of motives - ideological, strategic, opportunistic - to propose a particular tax-benefit system. By showing their budgets, we assumed that parties reveal their preferences. However, just like individuals, political parties may be subject to behavioral biases. For example, politicians may have difficulties understanding the difference between marginal and average tax rates, just like voters. If behavioral political biases are important, then revealed political preferences are no longer informative of true political preferences for income redistribution. A direction for future research is, therefore, to develop 'behavioral political economics' and how this would affect the inverse optimal-tax method.

\section{References}

Ahmad, Etisham, and Nicholas H. Stern (1984) 'The theory of reform and Indian indirect taxes.' Journal of Public Economics 25(3), 259-298

Alesina, Alberto, Andrea Ichino, and Loukas Karabarbounis (2011) 'Gender based taxation and the division of family chores.' American Economic Journal: Economic Policy 3(2), 1-40

Apps, Patricia F., and Ray Rees (1998) 'Taxation and the household.' Journal of Public Economics 35(3), 355-369

Atkinson, Anthony B., Thomas Piketty, and Emmanuel Saez (2011) 'Top incomes in the long run of history.' Journal of Economic Literature 49(1), 3-71

Bargain, Olivier, and Claire Keane (2011) 'Tax-benefit-revealed redistributive preferences over time: Ireland 1987 - 2005.' Labour 24, 141-167

Bargain, Olivier, Mathias Dolls, Dirk Neumann, Andreas Peichl, and Sebastian Siegloch (2013) 'Comparing inequality aversion across countries when labor supply responses differ.' International Tax and Public Finance 21(5), 845-873

- (2014) 'Tax-benefit revealed social preferences in Europe and the US.' Annals of Economics and Statistics 113-114, 257-289

\footnotetext{
${ }^{48}$ Furthermore, by explicitly deriving social welfare weights from revealed political preferences, governments can make interpersonal welfare comparisons, since social welfare weights can be used to measure the distributional costs and benefits of policies in social cost-benefit analysis, see also Hendren (2014).
} 
Bettendorf, Leon J., and Sijbren Cnossen (2014) 'Bouwstenen voor een moderne BTW.' CPB Policy Brief 2014-02 The Hague

Bierbrauer, Felix, and Pierre C. Boyer (2016) 'Efficiency, welfare, and political competition.' Quarterly Journal of Economics 131(1), 461-518

Blundell, Richard, and Thomas MaCurdy (1999) 'Labor supply: A review of alternative approaches.' In Handbook of Labor Economics, ed. Orley C. Ashenfelter and David Card, vol. 3 (Amsterdam: Elsevier) chapter 27, pp. 1559-1695

Blundell, Richard, Mike Brewer, Peter Haan, and Andrew Shephard (2009) 'Optimal income taxation of lone mothers: An empirical comparison of the UK and Germany.' Economic Journal 119(535), F101-F121

Boskin, Michael J., and Eytan Sheshinski (1983) 'Optimal tax treatment of the family: Married couples.' Journal of Public Economics 20(3), 281-297

Bourguignon, François, and Amedeo Spadaro (2012) 'Tax-benefit revealed social preferences.' Journal of Economic Inequality 10(1), 75-108

Brendon, Charles (2013) 'Efficiency, equity, and optimal income taxation.' EUI Working Papers MWP nr. 2013/22 Florence: EUI

Brett, Craig, and John A. Weymark (2014) 'Citizen candidates and voting over incentive-compatible nonlinear income tax schedules.' Center for the Study of Democratic Institutions Working Paper 6-2014 Santa Barbara, CA: CSDI

Brewer, Mike, Emmanuel Saez, and Andrew Shephard (2010) 'Means-testing and tax rates on earnings.' In The Mirrlees Review - Dimensions of Tax Design, ed. James A. Mirrlees, Stuart Adam, Timothy J. Besley, Richard Blundell, Steven Bond, Robert Chote, Malcolm Gammie, Paul Johnson, Gareth D. Myles, and James M. Poterba (Oxford: Oxford University Press) chapter 3, pp. 202-274

Chetty, Raj (2009) 'Sufficient statistics for welfare analysis: A bridge between structural and reduced-form methods.' Annual Review of Economics 1, 451-488

Christiansen, Vidar, and Eilev S. Jansen (1978) 'Implicit social preferences in the Norwegian system of iindirect taxation.' Journal of Public Economics 10(2), 217-245

Clauset, Aaron, Cosma R. Shalizi, and Mark E. Newman (2009) 'Power-law distributions in empirical data.' SIAM Review 51(4), 661-703

CPB (2002a) 'Charting Choices 2003-2006: Economic effects of eight election platforms.' CPB Document 19 The Hague

_ (2002b) 'Keuzes in Kaart: 2003-2006.' CPB Special Publication 39 The Hague 
CPB, and PBL (2012) 'Charted Choices 2013-2017: Effects of nine election platforms on the economy and the environment.' CPB Book 5 The Hague

Decoster, André, and Erik Schokkaert (1989) 'Equity and efficiency of a reform of Belgian indirect taxes.' Recherches Economiques de Louvain 55(2), 155-176

Diamond, Peter A. (1975) 'A many-person Ramsey tax rule.' Journal of Public Economics 4(4), 335342

_ (1980) 'Income taxation with fixed hours of work.' Journal of Public Economics 13(1), 101-110

_ (1998) 'Optimal income taxation: An example with a U-shaped pattern of optimal marginal tax rates.' American Economic Review 88(1), 83-95

Ebert, Udo (1992) 'A reexamination of the optimal nonlinear income tax.' Journal of Public Economics 49(1), 47-73

Evers, Michiel, Ruud A. de Mooij, and Daniel J. van Vuuren (2008) 'The wage elasticity of labour supply: A synthesis of empirical estimates.' De Economist 156(1), 25-43

Fuchs, Victor R., Alan B. Krueger, and James M. Poterba (1998) 'Economists' view about parameters, values and policies: Survey results in labor and public economics.' Journal of Economic Literature 36(3), 1387-1425

Gielen, Miriam D., Joke Goes, Marcel H. Lever, and Rocus M. Van Opstal (2009) 'Ontwikkeling en verdeling van de marginale druk 2001-2011.' CPB Document 195 The Hague

Graafland, Johan J., and Arie P. Ros (2003) Economic Assesment of Election Programmes: Does It Make Sense? (Dordrecht: Kluwer Academic Publishers)

Graafland, Johan J., Ruud A. de Mooij, André G. Nibbelink, and Ate Nieuwenhuis (2001) MIMICing Tax Policies and the Labour Market (Amsterdam: North-Holland)

Hendren, Nathaniel (2014) 'The inequality deflator: Interpersonal comparisons without a social welfare function.' NBER Working Paper 20351 Cambridge, MA

Jacobs, Bas (2015) De Prijs van Gelijkheid (Amsterdam: Bert Bakker-Prometheus)

Jacquet, Laurence, and Etienne Lehmann (2015) 'Optimal income taxation when skills and behavioral elasticities are heterogeneous.' CESifo Working Paper 5265 Munich

Jacquet, Laurence, Etienne Lehmann, and Bruno Van Der Linden (2013) 'Optimal redistributive taxation with both extensive and intensive responses.' Journal of Economic Theory 148(5), 17701805

Jongen, Egbert L., and Maaike Stoel (2013) 'Estimating the elasticity of taxable labour income in the Netherlands.' CPB Background Document The Hague 
Jongen, Egbert L., Henk-Wim de Boer, and Peter H. Dekker (2014) 'MICSIM: A behavioral microsimulation model for the analysis of tax-benefit reform in the Netherlands.' CPB Background Document The Hague

Kleven, Henrik J., Claus T. Kreiner, and Emmanuel Saez (2009) 'The optimal income taxation of couples.' Econometrica 77(2), 537-560

Kuhry, Bob, and Evert Pommer (2006) Publieke Productie en Persoonlijk Profijt. De Productie van Publieke dDiensten en Profijt van de Overheid, 1990-2003, (Den Haag: Sociaal en Cultureel Planbureau)

Lockwood, Benjamin B., and Matthew Weinzierl (2016) 'Positive and normative judgments implicit in U.S. tax policy, and the costs of unequal growth and recessions.' Journal of Monetary Economics

Lorenz, Normann, and Dominik Sachs (2016) 'Identifying Laffer bounds: A sufficient-statistics approach with an application to Germany.' Scandinavian Journal of Economics

Mankiw, N. Gregory, Matthew Weinzierl, and Danny Yagan (2009) 'Optimal taxation in theory and practice.' Journal of Economic Perspectives 23(4), 147-174

Mastrogiacomo, Mauro, Nicole M. Bosch, Miriam D. Gielen, and Egbert L. Jongen (2015) 'Heterogeneity in labour supply responses: Evidence from a major tax reform.' mimeo, CPB Netherlands Bureau for Economic Policy Analysis The Hague

Meghir, Costas, and David Phillips (2010) 'Labour supply and taxes.' In The Mirrlees Review Dimensions of Tax Design, ed. James A. Mirrlees, Stuart Adam, Timothy J. Besley, Richard Blundell, Steven Bond, Robert Chote, Malcolm Gammie, Paul Johnson, Gareth D. Myles, and James M. Poterba (Oxford: Oxford University Press) chapter 3, pp. 202-274

Melguizo, Ángel, and José M. González-Páramo (2013) 'Who bears labour taxes and social contributions? A meta-analysis approach.' SERIEs 4, 247-271

Meltzer, Allan H., and Scott F. Richard (1981) 'A rational theory of the size of government.' Journal of Political Economy 89(5), 914-927

Mirrlees, James A. (1971) 'An exploration in the theory of optimum income taxation.' Review of Economic Studies 38(2), 175-208

Mooij, Ruud A. de (2005) 'Will corporate income taxation survive?' De Economist 153(3), 277-301

Obama, Barack H. (2013) 'Remarks by the President on economic mobility.' The White House: Office of the Press Secretary Washington, D.C. Retrieved from http://www.whitehouse.gov/thepress-office/2013/12/04/remarks-president-economic-mobility 
Obama, Barack H. (2015) 'Speech at town hall meeting in Charlotte, North Carolina.' C-Span. Retrieved from: http://www.c-span.org/video/?325396-1/president-obama-town-hall-meetingcharlotte-north-carolina

OECD (2014) 'Benefits and Wages.' OECD, Paris

Olson, Mancur (1982) The Rise and Decline of Nations: Economic Growth, Stagflation, and Social Rigidities (New Haven and London: Yale University Press)

Persson, Torsten, and Guido Tabellini (2000) Political Economics: Explaining Economic Policy (Cambridge, MA: MIT press)

Piketty, Thomas (2014) Capital in the Twenty-First Century (Cambridge, MA: Harvard University Press)

Roberts, Kevin W. (1977) 'Voting over income tax schedules.' Journal of Public Economics $8(3), 329-340$

Röell, Ailsa A. (2012) 'Voting over nonlinear income tax schedules.' mimeo New York, NY: Columbia University

Roemer, John E. (1998) 'Why the poor do not expropriate the rich: An old argument in new garb.' Journal of Public Economics 70(3), 399-424

Roemer, John E. (1999) 'The democratic political economy of progressive income taxation.' Econometrica $67(1), 1-19$

Romer, Thomas (1975) 'Individual welfare, majority voting, and the properties of a linear income tax.' Journal of Public Economics 4(2), 163-185

Romney, W. Mitt (2012) 'Don't tax the job creators.' CNBC Interview Englewood Cliffs, New Jersey. Retrieved from: http://www.cnbc.com/id/48290347

Rutte, Mark (2012) 'Speech VVD congress.' Retrieved from: http://www.vvd.nl/nieuws/41/speech-rutte-op-verkiezingscongres

Saez, Emmanuel (2001) 'Using elasticities to derive optimal income tax rates.' Review of Economic Studies 68(1), 205-229

_ (2002) 'Optimal income transfer programs: Intensive versus extensive labor supply responses.' Quarterly Journal of Economics 117(3), 1039-1073

Saez, Emmanuel, and Stefanie Stantcheva (2016) 'Generalized social marginal welfare weights for optimal tax theory.' American Economic Review 106(1), 24-45

Saez, Emmanuel, Joel Slemrod, and Seth Giertz (2012) 'The elasticity of taxable income with respect to marginal tax rates: A critical review.' Journal of Economic Literature 50(1), 3-50 
Schroyen, Fred (2003) 'Redistributive taxation and the household: The case of individual filings.' Journal of Public Economics 87(11), 2527-2547

Socialist Party (2014) 'Spanning 5/2014.' Retrieved from: http://www.sp.nl

Statistics Netherlands (1999) 'WoningBehoefte Onderzoek 1998: Onderzoeksdocumentatie.' Heerlen/Voorburg

_ (2006) 'Microdatabestand CAPI/CATI Enquête beroepsbevolking 2006.' Heerlen/Voorburg

_ (2007) 'Documentatierapport Inkomens Panel Onderzoek (IPO) 2002V2.' Heerlen/Voorburg

_ (2015) 'Input-output tables 1995-2014.' Heerlen/Voorburg. Retrieved from: http://www.cbs.nl/nl-NL/menu/themas/macro-economie/cijfers/incidenteel/maatwerk/2012-io-cm.htm

Stern, Nicholas H. (1977) 'Welfare weights and the elasticity of the marginal valuation of income.' In Studies in Modern Economic Analysis, ed. Michael J. Artis and A. Robert Nobay (Oxford: Basil Blackwell Publishers)

Stigler, George J. (1970) 'Director's law of public income redistribution.' Journal of Law and Economics $13(1), 1-10$

Suyker, Wim B. (2013) 'Hoe sterk is de samenhang tussen regeerakkoord en doorgerekende verkiezingsprogramma's?' CPB Background Document The Hague

Terra-Pilaar, Paula A. (1999) 'MIMOS-2: microsimulatiemodel voor koopkrachtberekeningen.' CPB Interne Notitie The Hague

Tuomala, Matti (1984) 'On the optimal income taxation: Some further numerical results.' Journal of Public Economics 23(3), 351-366

Vermeulen, Wouter, and Jan Rouwendaal (2007) 'Housing supply in the netherlands.' CPB Discussion Paper No. 87 The Hague: CPB Netherland Bureau for Economic Policy Research

Werning, Iván (2007) 'Pareto efficient income taxation.' mimeo Cambridge, MA: MIT 


\section{A Proof Proposition 1}

\section{A.1 Optimal non-linear tax schedule}

In Jacquet et al. (2013) the government minimizes total resources subject to a set of constraints on the distribution of utilities and incentive compatibility constraints. Equation (28) of Jacquet et al. (2013) gives the optimal marginal tax rate for working individuals:

$$
\frac{T^{\prime}\left(z_{n}\right)}{1-T^{\prime}\left(z_{n}\right)}=\frac{\alpha_{n}}{\varepsilon_{n}^{c}} \frac{\left(\int_{n}^{\bar{n}} 1-g_{m}+\eta_{m} \frac{T^{\prime}\left(z_{m}\right)}{\left(1-T^{\prime}\left(z_{m}\right)\right)}-\zeta_{z_{m}}^{T} \frac{\tau_{z_{m}}}{1-\tau_{z_{m}}}\right) \tilde{k}(m) \mathrm{d} m}{(\tilde{K}(\bar{n})-\tilde{K}(n))} \frac{(\tilde{K}(\bar{n})-\tilde{K}(n))}{n \tilde{k}(n)}, \quad \forall n
$$

In this expression, $\alpha_{n} \equiv \frac{\partial z_{n}}{\partial n} \frac{n}{z_{n}}>0$ denotes the elasticity of gross earnings $z_{n}$ with respect to ability n. $\varepsilon_{n}^{c} \equiv-\frac{\partial z_{n}}{\partial T^{\prime}} \frac{\left(1-T^{\prime}\left(z_{n}\right)\right)}{z_{n}}>0$ is the compensated elasticity of taxable income. $\eta_{n}=-\left(1-T^{\prime}\left(z_{n}\right)\right) \frac{\partial z_{n}}{\partial \rho}$ $\geq 0$ is the income effect on gross earnings of workers with ability $n$, where $\rho$ is an exogenous change in income. $\tilde{k}(n) \equiv \int_{\underline{\varphi}}^{u_{n}-v(b)} k(n, \varphi) \mathrm{d} \varphi$, denotes the density of individuals with ability $n$ that participate in the labor market. $\tilde{K}(n)$ is the fraction of employed workers with ability less than or equal to $n$ in the population, where $\tilde{K}(n) \equiv \int_{\underline{n}}^{n} \tilde{k}(m) \mathrm{d} m$. Finally, $\zeta_{z_{m}}^{T} \equiv \frac{k\left(n, u_{n}-v(b)\right)}{\tilde{k}(n)} u_{c}(\cdot)(z-(T(z)+b))>0$ is the participation elasticity with respect to a change in participation taxes. ${ }^{49}$

It will be impossible to bring equation (A.1) to the data, since ability and disutility of participation are unobservable. Hence, we cannot measure $\tilde{K}(n)$. Moreover, while the monotonicity of the optimal second-best allocation guarantees a one-to-one mapping between the ability of employed workers and their gross earnings, such a mapping does not exist for the non-employed. However, Bayes theorem allows us to decompose $\tilde{K}(n)$ into the distribution of income among the employed and the employment rate. Since both are observable from the data, we can rewrite equation (A.1) in terms of sufficient statistics. In particular, note that by definition we can write $\tilde{K}(n)$ as:

$$
\tilde{K}(n)=\int_{\underline{n}}^{n} \int_{\underline{\varphi}}^{u_{n}-v(b)} k(m, \varphi) \mathrm{d} \varphi \mathrm{d} m \equiv P\left(n_{i} \leq n, e_{i}=1\right), \quad \forall n .
$$

where $e_{i}$ is an indicator variable, which takes value 1 if individual $i$ is employed, and zero if the individual is not employed. $P\left(n_{i} \leq n, e_{i}=1\right)$ denotes the probability that a random individual $i$ in the population has an ability $n_{i}$ smaller than or equal to $n$ and is employed. In words: the fraction of the population that is employed and has ability smaller than $n$ equals the joint probability that a random individual is employed and has ability smaller than or equal to $n$. By Bayes theorem we can rewrite this probability as:

$$
P\left(n_{i} \leq n, e_{i}=1\right)=P\left(n_{i} \leq n \mid e_{i}=1\right) P\left(e_{i}=1\right), \quad \forall n,
$$

where $P\left(n_{i} \leq n \mid e_{i}=1\right)$ denotes the probability that a random individual $i$ in the population

\footnotetext{
${ }^{49}$ Note that we use slightly different definitions of the income and participation elasticities than in Jacquet et al. (2013). In particular, their income elasticity is defined as $\eta_{n}=-\frac{\partial z_{n}}{\partial \rho} \geq 0$ and their participation elasticity is defined as: $\kappa_{n}=\frac{k\left(u_{n}-v(b), n\right)}{\tilde{k}(n)} u_{c}(\cdot)$.
} 
has ability smaller than or equal to $n_{i}$ conditional on being employed, and $P\left(e_{i}=1\right)$ is the unconditional probability that a random person $i$ is employed. Note that $P\left(e_{i}=1\right)$ equals the employment rate $E \equiv \int_{\underline{n}}^{\bar{n}} \int_{\underline{\varphi}}^{u_{n}-v(b)} k(m, \varphi) \mathrm{d} \varphi \mathrm{d} m$. Using $\tilde{K}(n)=\int_{\underline{n}}^{n} \int_{\underline{\varphi}}^{u_{n}-v(b)} k(m, \varphi) \mathrm{d} \varphi \mathrm{d} m$, the conditional probability $P\left(n_{i} \leq n \mid e_{i}=1\right)$ is thus equal to:

$$
P\left(n_{i} \leq n \mid e_{i}=1\right)=\frac{\int_{\underline{n}}^{n} \int_{\underline{\varphi}}^{u_{n}-v(b)} k(m, \varphi) \mathrm{d} \varphi \mathrm{d} m}{\int_{\underline{n}}^{\bar{n}} \int_{\underline{\varphi}}^{u_{n}-v(b)} k(m, \varphi) \mathrm{d} \varphi \mathrm{d} m} .
$$

Since there is a monotonic mapping between ability $n$ and gross earnings $z_{n}$ among employed individuals, the probability that an individual has ability smaller than $n$ conditional on employment equals the probability that an individual has an income below $z_{n}$ conditional on employment: $P\left(n_{i} \leq n \mid e_{i}=1\right) \equiv P\left(z_{i} \leq z_{n} \mid e_{i}=1\right)$. Hence, we can decompose $\tilde{K}(n)$ entirely into observables $F\left(z_{n}\right)$ and $E$ :

$$
\tilde{K}(n)=F\left(z_{n}\right) E, \quad \forall n, z_{n} .
$$

Further, to find an expression for $\tilde{k}(n)$ in terms of observables, take the derivative of equation (A.5) with respect to ability:

$$
\tilde{k}(n) \equiv \frac{\mathrm{d} \tilde{K}(n)}{\mathrm{d} n}=\frac{\mathrm{d} F\left(z_{n}\right)}{\mathrm{d} n} E=f\left(z_{n}\right) \frac{\mathrm{d} z_{n}}{\mathrm{~d} n} E=f\left(z_{n}\right) \alpha_{n} \frac{z_{n}}{n} E, \quad \forall n, z_{n}
$$

In the second step, we have used the definition of $\tilde{K}(n)$ and $\alpha_{n}$, and the fact that the overall employment rate is independent of ability. We can simplify (A.1) by substituting equations (A.5) and (A.6) to arrive at:

$$
\frac{T^{\prime}\left(z_{n}\right)}{1-T^{\prime}\left(z_{n}\right)}=\frac{1}{\varepsilon_{n}^{c}} \frac{\left(\int_{z_{n}}^{\bar{z}} 1-g_{m}+\eta_{m} \frac{T^{\prime}\left(z_{m}\right)}{\left(1-T^{\prime}\left(z_{m}\right)\right)}-\zeta_{z_{m}}^{T} \frac{\tau_{z_{m}}}{\left(1-\tau_{z_{m}}\right)}\right) f\left(z_{m}\right) \mathrm{d} z_{m}}{\left(1-F\left(z_{n}\right)\right)} \frac{\left(1-F\left(z_{n}\right)\right)}{f\left(z_{n}\right) z_{n}}, \quad \forall z_{n},
$$

where $\bar{z} \equiv z_{\bar{n}}$, and we have used the fact that $F(\bar{z})=1$. Moreover, for the term inside the integral we have used that (A.6) can be rewritten as $\tilde{k}(n) \mathrm{d} n=f\left(z_{n}\right) \mathrm{d} z_{n} E$. Note that by the substitution rule for integration, the bounds of the integrals change.

We can write equation (A.7) completely in terms of earnings $z$. Due to the monotonic mapping from $n$ to $z_{n}$ there exists (with slight abuse of notation) an $x_{z_{n}}$ such that $x_{z_{n}} \equiv x_{n}$ for all parameters $x=\left\{g, \eta, \kappa, \varepsilon^{c}\right\}$ and for all $z_{n}$. In addition, we can rewrite the expression for any particular $z \in[\underline{z}, \bar{z}]$, because equation (A.7) holds for all $z_{n} \in[\underline{z}, \bar{z}]$. Using these results and dropping the $n$-subscripts allows us to write expression (A.7) as equation (5) in the main text. 


\section{A.2 Optimal participation tax}

The optimality condition for the participation tax is given by equation (18d) in Jacquet et al. (2013):

$$
\left(g_{0}-1\right) \int_{\underline{n}}^{\bar{n}} \int_{u_{n}-v(b)}^{\bar{\varphi}} k(n, \varphi) \mathrm{d} \varphi \mathrm{d} n=\int_{\underline{n}}^{\bar{n}}\left(T\left(z_{n}\right)+b\right) v^{\prime}(b) k\left(n, u_{n}-v(b)\right) \mathrm{d} n .
$$

Note that this equation is, again, written in terms of the unobservable joint density function $k(n, \varphi)$.

To express the equation in terms of the income distribution among workers and the employ-

ment rate, note that the non-employment rate equals $1-E=\int_{n}^{\bar{n}} \int_{u_{n}-v(b)}^{\bar{\varphi}} k(n, \varphi) \mathrm{d} \varphi \mathrm{d} n$. Moreover, using the definition of the participation elasticity with respect to a change in benefits, i.e., $\zeta_{z}^{b} \equiv \frac{k\left(n, u_{n}-v(b)\right)}{\tilde{k}(n)} v^{\prime}(b)(z-(T(z)+b))$, we find:

$$
k\left(n, u_{n}-v(b)\right)=\frac{\zeta_{z_{n}}^{b} \tilde{k}(n)}{v^{\prime}(b)\left(z_{n}-\left(T\left(z_{n}\right)+b\right)\right)} .
$$

Consequently, we can write the optimal participation tax as:

$$
\left(g_{0}-1\right)(1-E)=\int_{\underline{n}}^{\bar{n}} \zeta_{z_{n}}^{b} \frac{\tau_{z_{n}}}{\left(1-\tau_{z_{n}}\right)} \tilde{k}(n) \mathrm{d} n .
$$

Now, use $\tilde{k}(n)=f\left(z_{n}\right) \frac{\mathrm{d} z_{n}}{\mathrm{~d} n} E$, change the variables of integration and drop the subscripts $n$ to arrive at expression (6) for the optimal participation tax in the main text.

\section{B Proof Proposition 2}

Using Leibniz' rule we can differentiate the optimal income tax (5) with respect to $z$ :

$$
\begin{aligned}
\frac{1}{f(z)} \frac{\mathrm{d}\left(\frac{T^{\prime}(z)}{1-T^{\prime}(z)} \varepsilon_{z}^{c} f(z) z\right)}{\mathrm{d} z} & =\varepsilon_{z}^{c} z \frac{\mathrm{d}\left(\frac{T^{\prime}(z)}{1-T^{\prime}(z)}\right)}{\mathrm{d} z}+\frac{z T^{\prime}(z)}{\left(1-T^{\prime}(z)\right)} \frac{\mathrm{d} \varepsilon_{z}^{c}}{\mathrm{~d} z}+\frac{\varepsilon_{z}^{c} T^{\prime}(z)}{f(z)\left(1-T^{\prime}(z)\right)} \frac{\mathrm{d}(f(z) z)}{\mathrm{d} z} \\
& =\left(\theta_{z}+\xi_{z}\right) \varepsilon_{z}^{c} \frac{T^{\prime}(z)}{\left(1-T^{\prime}(z)\right)}+\varepsilon_{z}^{c} \frac{z T^{\prime \prime}(z)}{\left(1-T^{\prime}(z)\right)^{2}}
\end{aligned}
$$

Use equation (B.1) to arrive at equation (7) in the main text. Finally, reorder (A.10) to arrive at equation (9) in the main text.

\section{Calibration of the model}

\section{C.1 Social welfare weights in terms of structural parameters}

In this appendix we express the social welfare weights in terms of structural parameters. Once we have calibrated the structural model, we can easily calculate the social welfare weights. After that, we describe the calibration procedure to fit the structural model to the data. 
Equation (A.1) gives the formula for the optimal tax schedule. By inverting this expression we can solve for the welfare weights of working individuals in terms of structural model parameters:

$$
g_{n}=1+\eta_{n} \frac{T^{\prime}\left(z_{n}\right)}{\left(1-T^{\prime}\left(z_{n}\right)\right)}-\zeta_{n}^{T} \frac{\tau_{z_{n}}}{\left(1-\tau_{z_{n}}\right)}+\frac{1}{\tilde{k}(n)} \frac{\mathrm{d}\left[\frac{\varepsilon_{m}^{c}}{\alpha_{m}} \frac{T^{\prime}\left(z_{m}\right)}{1-T^{\prime}\left(z_{m}\right)} m \tilde{k}(m)\right]}{\mathrm{d} m}, \quad \forall n
$$

In addition, we find the welfare weight for non-participants by solving equation (A.10) for $g_{0}$ :

$$
g_{0}=1+\frac{\int_{\underline{n}}^{\bar{n}} \zeta_{n}^{b} \frac{\tau_{z_{n}}}{\left(1-\tau_{z_{n}}\right)} \tilde{k}(n) \mathrm{d} n}{1-E}
$$

We express the behavioral elasticities in equations (C.1) and (C.2) in terms of structural parameters as follows: ${ }^{50}$

$$
\begin{aligned}
\alpha_{n} & =\frac{\frac{n}{z_{n}}\left(\frac{u_{l}}{n^{2}}+\frac{l u_{l l}}{n^{2}}\right)}{\frac{u_{l l}}{n^{2}}+\left(1-T^{\prime}\left(z_{n}\right)\right)^{2} u_{c c}-T^{\prime \prime}\left(z_{n}\right) u_{c}}, \\
\eta_{n} & =\frac{\left(1-T^{\prime}\left(z_{n}\right)\right)^{2} u_{c c}}{\frac{u_{l l}}{n^{2}}+\left(1-T^{\prime}\left(z_{n}\right)\right)^{2} u_{c c}-T^{\prime \prime}\left(z_{n}\right) u_{c}} \\
\varepsilon_{n}^{c} & =\frac{\frac{u_{l}}{n z_{n}}}{\frac{u_{l l}}{n^{2}}+\left(1-T^{\prime}\left(z_{n}\right)\right)^{2} u_{c c}-T^{\prime \prime}\left(z_{n}\right) u_{c}}, \\
\zeta_{n}^{T} & =\frac{k\left(u_{n}-v(b), n\right)}{\tilde{k}(n)}\left(z_{n}-T\left(z_{n}\right)-b\right) u_{c}, \\
\zeta_{n}^{b} & =\frac{v^{\prime}(b)}{u_{c}} \zeta_{n}^{T} .
\end{aligned}
$$

Before we turn to the calibration algorithm, we employ a number of structural assumptions to simplify the expression for the social welfare weights in equation (C.1). First, under the specific form of our utility function, equation (13), $\frac{\varepsilon_{n}^{c}}{\alpha_{n}}$ in equation (C.1) simplifies to:

$$
\frac{\varepsilon_{n}^{c}}{\alpha_{n}}=\frac{\varepsilon}{1+\varepsilon}
$$

Second, we assume $n$ and $\varphi$ are distributed independently. This allows us to write $k(n, \varphi) \equiv$ $h(n) \hat{k}(\varphi)$ where $h(n)$ is the unconditional probability density function of $n$ and $\hat{k}(\varphi)$ is the probability density function of $\varphi$. Using the definition of $\tilde{k}(n)$, we can therefore write:

$$
\tilde{k}(n) \equiv \int_{-\infty}^{u_{n}-v(b)} k(n, \varphi) \mathrm{d} \varphi=h(n) \int_{-\infty}^{u_{n}-v(b)} \hat{k}(\varphi) \mathrm{d} \varphi=h(n) \hat{K}\left(u_{n}-v(b)\right),
$$

where $\hat{K}(\varphi) \equiv \int_{-\infty}^{\varphi} \hat{k}\left(\varphi^{\prime}\right) \mathrm{d} \varphi^{\prime}$ is the cumulative density function of participation costs. This, in

\footnotetext{
${ }^{50}$ See equation (7), and (25a-c) in Jacquet et al. (2013) for the derivation, where we assume $u\left(c_{n}, z_{n}, n\right)=u\left(c_{n}, l_{n}\right)$ and $u_{c l}=0$, which is consistent with our utility function in equation (13).
} 
turn, allows us to simplify the expression for the participation elasticity as follows:

$$
\zeta_{n}^{T}=\frac{\hat{k}\left(u_{n}-v(b)\right)}{\hat{K}\left(u_{n}-v(b)\right)}\left(z_{n}-T\left(z_{n}\right)-b\right) u_{c} .
$$

Using equations (C.8) and (C.9), we can rewrite the final term in equation (C.1) in the following way:

$$
\begin{aligned}
\frac{1}{\tilde{k}(n)} \frac{\mathrm{d}\left[\frac{\varepsilon_{m}^{c}}{\alpha_{m}} \frac{T^{\prime}\left(z_{m}\right)}{1-T^{\prime}\left(z_{m}\right)} m \tilde{k}(m)\right]}{\mathrm{d} m}= & \frac{1}{h(n) \hat{K}\left(u_{n}-v(b)\right)} \frac{\mathrm{d}\left[\frac{\varepsilon}{\varepsilon+1} \frac{T^{\prime}\left(z_{m}\right)}{1-T^{\prime}\left(z_{m}\right)} m h(m) \hat{K}\left(u_{m}-v(b)\right)\right]}{\mathrm{d} m} \\
= & \frac{\varepsilon}{(1+\varepsilon)} \frac{T^{\prime}\left(z_{n}\right)}{1-T^{\prime}\left(z_{n}\right)}\left(\frac{n}{\hat{K}\left(u_{n}-v(b)\right)} \frac{\mathrm{d} \hat{K}\left(u_{m}-v(b)\right)}{\mathrm{d} m}+\theta_{n}^{n}\right) \\
& +\frac{n \varepsilon}{(1+\varepsilon)} \frac{\mathrm{d}\left[\frac{T^{\prime}\left(z_{m}\right)}{1-T^{\prime}\left(z_{m}\right)}\right]}{\mathrm{d} m},
\end{aligned}
$$

where $\theta_{n}^{n} \equiv 1+\frac{\mathrm{d} h(m)}{\mathrm{d} m} \frac{n}{h(n)}$ is the local elasticity of the tax base. The first step follows from substituting eqs. (C.8) and (C.9), and the second step follows from application of the product rule.

\section{C.2 Algorithm}

The algorithm that calculates the social welfare weights for the political parties uses four steps.

1. Calculate the allocation $\left\{z_{n}, c_{n}\right\}$ associated with the baseline marginal tax rates and income levels $\left\{T\left(z_{n}\right), b\right\}$.

2. Calibrate the parameters of the utility function $\{\alpha, \varepsilon, \gamma\}$, and estimate the conditional distribution of earnings ability for the working population $h\left(n \mid e_{i}=1\right)$ on the baseline data.

3. Estimate the distribution of participation costs $\hat{k}(\varphi)$ and the distribution of earnings ability for the entire population $h(n)$, again using baseline data.

4. Calculate the social welfare weights $g_{n}$ and $g_{0}$ based on the tax-benefit systems proposed by political parties using equations (C.1) and (C.2).

To determine the allocation and to find the tax function in the current tax-benefit system $T\left(z_{n}\right)$ we estimate a kernel regression of income on marginal tax rates to obtain a smoothed estimate of the marginal tax rate $T^{\prime}\left(z_{n}\right)$ at each income level. We subsequently calculate the total tax burden at each income level, excluding $T(0)$, using $\int_{z_{\underline{n}}}^{z_{n}} T^{\prime}\left(z_{n}\right) \mathrm{d} z_{n}$. We employ the government budget constraint (4) to find $T(0)$ and $b$, where $T(0)$ and $b$ are chosen such that i) the government budget constraint is satisfied, and ii) the average model-predicted participation tax rate equals the average participation tax rate calculated by CPB in the baseline. We then calculate total tax burdens $T\left(z_{n}\right)$ and obtain $c_{n}=z_{n}-T\left(z_{n}\right)$. 
In step 2 and 3 of our algorithm we employ the baseline allocation to calibrate $u\left(c_{n}, l_{n}\right), h(n)$ and $\hat{k}(\varphi)$. We first choose starting values for the utility parameters $\alpha, \gamma$ and $\varepsilon$. We then find the ability level of each individual in the sample by inverting their first-order condition, see also Saez (2001). This provides us with the following solution for individual ability in terms of their income level $z_{n}$, the tax function $T\left(z_{n}\right)$ and the utility parameters $\alpha, \gamma$ and $\varepsilon$ :

$$
n=\frac{\gamma^{\frac{\varepsilon}{1+\varepsilon}} z_{n}^{\frac{1}{1+\varepsilon}}\left(z_{n}-T\left(z_{n}\right)\right)^{\frac{\alpha \varepsilon}{1+\varepsilon}}}{\left(1-T^{\prime}\left(z_{n}\right)\right)^{\frac{\varepsilon}{1+\varepsilon}}}
$$

To find the distribution of earnings ability we estimate a kernel density function for ability. We will denote this distribution by $h\left(n \mid e_{i}=1\right)$, which is the distribution of ability conditional on employment. We approximate the top 10 percent of the ability distribution with a Pareto distribution. Since the top of the income distribution follows a Pareto distribution with a Pareto parameter of 3.25, it follows that the Pareto parameter for the ability distribution at the top is given by $a_{n}^{n}=3.25\left(1+\varepsilon^{u}\right)$, see Saez (2001, p.222). When we paste the Pareto tail to the ability distribution we scale the resulting distribution by two constants which ensure that i) the probability density function of ability is continuous around the cutoff, and ii) the integral over the distribution equals 1 . We evaluate the resulting distribution of ability at 150 linearly spaced points between the lowest and the highest ability level in our sample. Note that the estimated ability distribution at this stage is conditional on employment, since we cannot infer earnings ability for non-participants in the labor market. We denote the ability distribution conditional on employment by $h\left(n \mid e_{i}=1\right)$.

Next, we calculate the compensated and income earnings supply elasticities for all working individuals using equations (C.4) and (C.5). The average earnings supply and income elasticities among workers are given by $\bar{\varepsilon}^{c}=\int \varepsilon_{n}^{c} h\left(n \mid e_{i}=1\right) \mathrm{d} n$ and $\bar{\eta}=\int \eta_{n} h\left(n \mid e_{i}=1\right) \mathrm{d} n$. We iterate over different values of $\alpha, \gamma$ and $\varepsilon$, while updating the ability distribution through equation (C.12) at each iteration until: i) the model produces average elasticities that are equal to their empirical estimates, and ii) the average ability level equals the average income level in the sample. Although $\varepsilon_{n}^{c}$ and $\eta_{n}$ may theoretically depend on ability as well as on the tax schedule with our utility function, we find that the elasticities are roughly constant in both dimensions in our calibrated model. See Appendix D.

In the third step, we estimate the distribution of participation $\operatorname{costs} \hat{k}(\varphi)$. Ideally, we would like to estimate the parameters of $\hat{k}(\varphi)$ using ability-specific employment rates and extensive-margin elasticities. Unfortunately, these data are not available. However, as discussed in Section 3, we do have average extensive-margin elasticity by income quartiles. Since there is a one-to-one mapping between income and ability in our model, we can employ this information to calibrate $\hat{k}(\varphi)$. In particular, our model predicts an average participation elasticity for individuals between ability level $n_{1}$ and $n_{2}$ that equals:

$$
\zeta_{n}^{T}=\frac{\int_{n_{1}}^{n_{2}} \zeta_{n}^{T} h(m) \mathrm{d} m}{\int_{n_{1}}^{n_{2}} h(m) \mathrm{d} m}
$$


We can compare the predicted elasticity to the empirical estimate for this elasticity in the relevant income range.

Moreover, as discussed in section 3, we have education-specific employment rates for 5 different levels of education. When we assume there is also a one-to-one relationship between education and ability, the data provide us with the empirical employment rate at 5 points in the ability distribution. Our model predicts the following ability-specific employment rate:

$$
E_{n}=\hat{K}\left(u_{n}-v(b)\right)
$$

Hence, the predicted average employment rate between ability level $n_{1}$ and $n_{2}$ is given by:

$$
\bar{E}_{n}=\frac{\int_{n_{1}}^{n_{2}} \hat{K}\left(u_{m}-v(b)\right) h(m) \mathrm{d} m}{\int_{n_{1}}^{n_{2}} h(m) \mathrm{d} m} .
$$

The predicted employment rates by education level can, again, be compared to participation rates for the corresponding education group.

Overall we thus have 4 data points on the extensive-margin elasticity and 5 data points on the employment rates, which allow us to estimate parameters $\mu, \sigma$, and $\nu$ of $\hat{k}(\varphi)$ using a nonlinear least squares regression, where the error term consists of the difference between actual, and model-predicted extensive-margin elasticities and participation rates.

The predicted elasticities depend on $h(n)$ rather than $h\left(n \mid e_{i}=1\right)$, since extensive-margin elasticities depend both on responses of employed and non-employed individuals. We initially assume that $h\left(n \mid e_{i}=1\right)=h(n)$. Subsequently, we use the estimated $\hat{k}(\varphi)$ to retrieve the ability distribution $h(n)$ as follows. Let $e_{i}$ be an indicator equal to 1 when random individual $i$ is employed. Then, we find using Bayes' law:

$$
P\left(e_{i}=1 \mid n\right) h(n)=h\left(n \mid e_{i}=1\right) P\left(e_{i}=1\right) .
$$

The probability of being employed, conditional on employment is the ability-specific employment rate: $P\left(e_{i}=1 \mid n\right)=E_{n}$. The unconditional employment probability is the overall employment rate $P\left(e_{i}=1\right)=E$. We can thus rewrite (C.16) to arrive at:

$$
h(n)=\frac{h\left(n \mid e_{i}=1\right) E}{E_{n}}
$$

which gives us an updated estimate of $h(n)$. With this updated value we rerun the algorithm to determine updated values of $\mu, \sigma$ and $\nu$. The loop ends when the absolute value of the update on the parameters is below 0.1 percent. After step 3 we have thus calibrated $u\left(c_{n}, l_{n}\right), h(n)$, and $\hat{k}(\varphi)$.

The final step of the algorithm calculates social welfare weights using equation (C.1) for the welfare weights of the employed, and equation (C.2) for the non-employed. 


\section{Supplementary figures baseline}

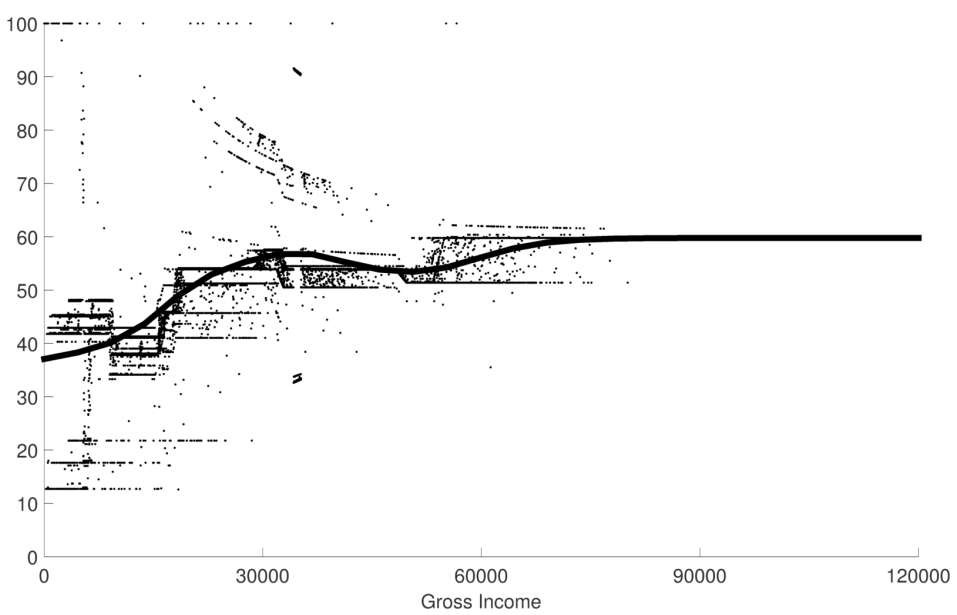

Figure D.1: Marginal tax rates in the baseline

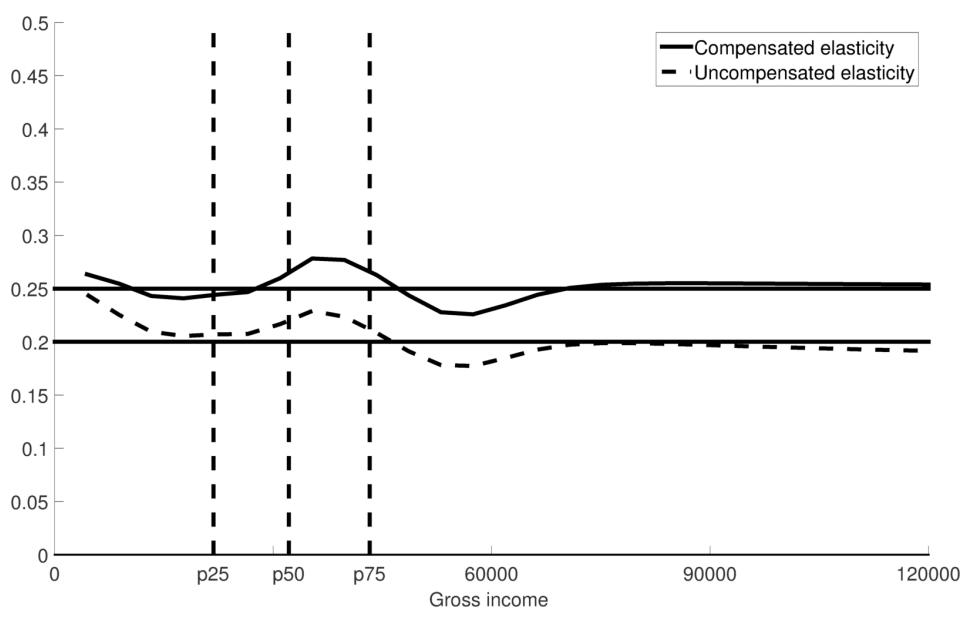

Figure D.2: Compensated and uncompensated intensive-margin elasticities by income 


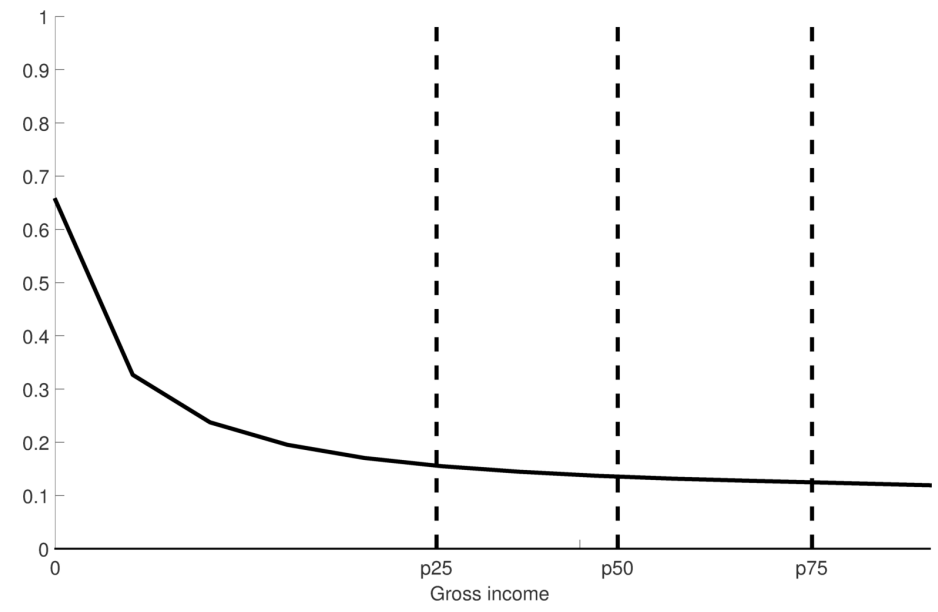

Figure D.3: Participation elasticity by income

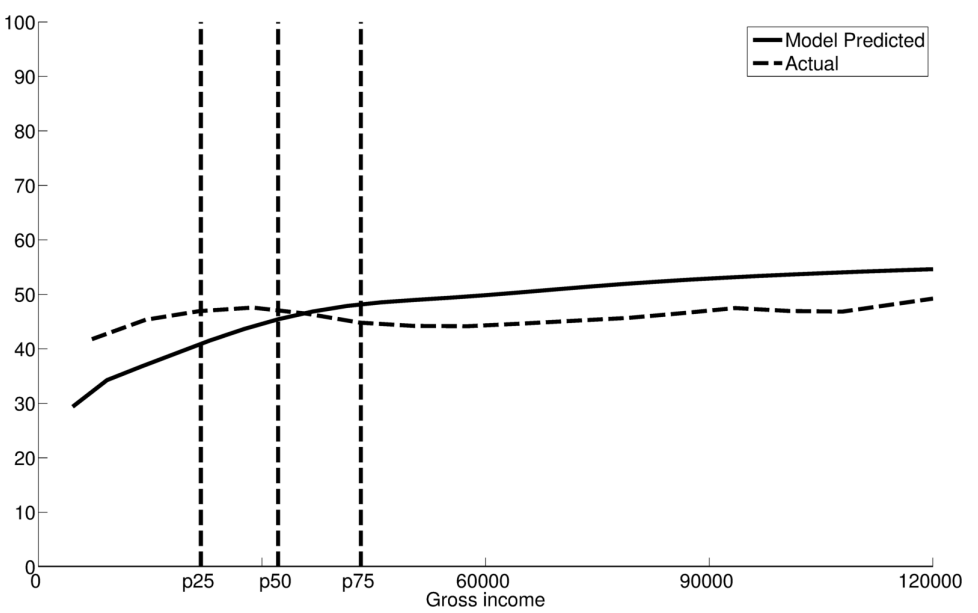

Figure D.4: Differences in model-predicted participation taxes and observed participation taxes 


\section{E Redistribution via in-kind transfers}

Table E.1: Distribution of government expenditures by decile of net after-tax household incomes ${ }^{a}$

\begin{tabular}{lrrrrrrrrrr}
\hline $\begin{array}{l}\text { Household income decile } \\
\text { Average disposable }\end{array}$ & 1 & 2 & 3 & 4 & 5 & 6 & 7 & 8 & 9 & 10 \\
household income & 2900 & 10800 & 14700 & 18000 & 21500 & 25400 & 30000 & 34900 & 41700 & 64100 \\
\hline Public transport & & & & & & & & & \\
Culture and recreation & 407 & 146 & 148 & 163 & 182 & 228 & 222 & 221 & 254 & 292 \\
Public services $^{\text {Housing }}{ }^{b}$ & 219 & 190 & 242 & 262 & 279 & 388 & 473 & 520 & 609 & 688 \\
Cost of living supplements $^{c}$ & 42 & 59 & 130 & 78 & 42 & 40 & 93 & 115 & 174 & 231 \\
\hline Total net benefit & 10 & 22 & 20 & 18 & 22 & 19 & 14 & 11 & 6 & 4 \\
Implicit marginal tax rate (\%) & 50 & 156 & 118 & 65 & 26 & 14 & 11 & 4 & 2 & 1 \\
\hline
\end{tabular}

${ }^{a}$ Source: Own calculations using Kuhry and Pommer (2006). ${ }^{b}$ Excluding rent subsidies, which are already included in the baseline. ${ }^{c}$ Excluding social assistance benefits, which are already included in the baseline.

Table E.1 gives the implicit marginal tax rate due to in-kind transfers by different deciles of disposable household income. The data are taken from Kuhry and Pommer (2006), where we have made a number of adjustments. First, the analysis in Kuhry and Pommer (2006) is based on a sample for the entire Dutch population, whereas our analysis focusses on employed individuals only. Since students and elderly are not included in our analysis, we set spending for higher education and long-term care to zero. Furthermore, we exclude the publicly provided private goods that are already taken into account in the calculations of the EMTRs and PTRs in the baseline: the health-insurance system, rent subsidies, and the tax deductibility of health-related expenses not covered by the health-insurance system. Also, we exclude expenditures for housing via the mortgage-rent deductibility and imputed rent, since these are not included in the calculation of marginal tax rates either, see also footnote 24 in the main text. Finally, we exclude spending on basic and intermediate education because labor supply on the intensive margin is not determined by education expenditures on children. That is, when an individual decides to work more hours, this does not change the expenditures on the education of his or her children.

We calculate the implicit marginal tax rates on net income due to the expenditure side of the public budget as $\frac{\Delta S}{\Delta c}=\frac{S_{i}-S_{j}}{c_{i}-c_{j}}$, where $S_{i}$ and $S_{j}$ denote the average net benefits of government expenditures and $c_{i}$ and $c_{j}$ denote the average net household incomes in deciles $i$ and $j$ (where $c_{i}>c_{j}$ ). From Table E.1 we can conclude that the EMTRs change little when including in-kind transfers. Moreover, this is an upper bound, since changes in EMTRs in terms of gross household income are even smaller. We cannot calculate the social welfare weights including in-kind transfers, since we lack the data to map changes in EMTRs and PTRs based on disposable household incomes to changes in EMTRs and PTRs based on individual gross incomes. However, the changes should be small given that the change in EMTRs and PTRs will be small. 


\section{F Political parties in the Netherlands}

Table F.1: Political parties in the national elections of $2002^{a}$

\begin{tabular}{lllrrr}
\hline Name & Acronym & Profile & $\begin{array}{r}\text { Seats before } \\
\text { 2002 election }\end{array}$ & $\begin{array}{r}\text { Seats after } \\
\text { 2002 election }\end{array}$ & $\begin{array}{r}\text { Seats after } \\
\text { 2012 election }\end{array}$ \\
\hline $\begin{array}{l}\text { Partij van de Arbeid } \\
\text { Volkspartij voor }\end{array}$ & PvdA & Social democrat & 45 & 23 & 38 \\
Vrijheid en Democratie & & Conservative liberal & 38 & 24 & 41 \\
Christen Democratisch & CDA & Christian democrat & & & \\
Appèl & & & 29 & 43 & 13 \\
Democraten 66 & D66 & Social liberal & 14 & 7 & 20 \\
GroenLinks & GL & Environmental progressive & 11 & 10 & 4 \\
Socialistische Partij & SP & Socialist & 5 & 9 & 15 \\
ChristenUnie & CU & Protestant orthodox & 5 & 4 & 5 \\
Staatkundig Gerefor- & SGP & Protestant orthodox & 3 & 2 & 3 \\
meerde Partij & & & & & \\
Lijst Pim Fortuyn & LPF & Anti political establishment & - & 26 & - \\
Leefbaar Nederland & LN & Anti political establishment & - & 2 & - \\
\hline
\end{tabular}

${ }^{a}$ Source: Graafland and Ros (2003) and www.tweedekamer.nl.

The Dutch parliament is called States General and consists of two bodies. The Second Chamber, or Lower House of the Dutch parliament contains 150 seats. The First Chamber, or Upper House or Senate, contains 75 seats. The Second Chamber is the most important body, since it has legislative powers, such as the right of amendment. The First Chamber can only approve or reject of legislation that has been proposed by the Second Chamber. Throughout our paper we focus on the second Chamber. Seats for the Second Chamber are awarded through national elections, at least every 4 years, unless the ruling (coalition) government breaks down at an earlier date. The Netherlands has a system of party-list proportional representation. That is, if a party gets $x$ percent of the votes in the country it is awarded with $1.5 x$ seats.

Table F.1, based on Graafland and Ros (2003), provides an overview of the political parties that received votes in the 2002 elections. We added the most recent, 2012-election outcomes. Political parties are ordered according to their seats in parliament in the period 1998-2002, before the elections in 2002. The 2002 elections were preceded by two periods with so-called 'purple' governments: Kok-I from 1994-1998, and Kok-II from 1998-2002, named after prime minister Wim Kok. These ruling governments consisted of the center-left PvdA, right-wing VVD, and the smaller, center party D66. They had 97 of a total of 150 seats in parliament before the 2002 elections. However, in a short period of time Pim Fortuyn and his populist party LPF became very popular. Pim Fortuyn was murdered in the run-up to the 2002 elections, but his party still obtained 26 seats in the Second Chamber. They formed a coalition together with CDA and VVD, which fell apart less than one year later. The more traditional parties CDA, VVD, and D66 then formed a new 
coalition. Since the beginning of the century many coalition governments have proven unstable. Indeed, there have been 5 general elections between 2002 and 2012. Since 2012 the ruling coalition consists of VVD and PvdA.

\section{G Detailed tax-benefit proposals political parties}

We use the data from the policy packages that political parties submitted for analysis to CPB Netherlands Bureau for Economic Policy Analysis in 2002. ${ }^{51}$ Clearly, not all party proposals are related to income redistribution. Below we outline the policy changes that are most relevant for our analysis: the proposed changes in taxes on labor income, corporate taxes, tax on consumption, taxes on capital income, and benefits for the non-employed. The resulting scatter plots for the effective marginal tax rates are shown in Figure G.1.

\footnotetext{
${ }^{51} \mathrm{CPB}$ (2002b) gives an extensive overview of the proposed policy changes and the resulting effects in Dutch. A brief English summary can be found in CPB (2002a).
} 
Table G.1: Proposed changes by the Socialist Party (SP) ${ }^{a}$

Effect on government budget (in billion euro)

Labor taxes

- Abolishment of health-care premiums households $\quad-8.05$

- Across-the-board increase in tax bracket rates of 3 percentage points $\quad+8.20$

- Reduction in first tax bracket rate of -0.7 percentage points

- Introduction of a fifth bracket beyond 213,358 euro with a rate of 72 percent

- Higher earned-income tax credit

$-1.80$

- Income-dependent tax credit elderly

Corporate taxes

- Reduction in unemployment insurance premiums for employers

- Abolishment of employer subsidies for low-wage workers

- Abolishment of various types of employer subsidies

- Higher corporate income tax

- Experience rating disability benefits employers

- Tax on emissions by planes

- Tax on empty seats on planes

- Abolishment of sewage taxes

Capital income taxes

- Abolishment of deductability of mortgage interest rate payments for mortgages in excess of 190,000 euro

- Tax on land

- Abolishment of presumptive capital income tax

- Introduction capital gains tax

- Introduction of wealth tax

Benefits non-employed

- Increase in benefits linked to the social minimum by 5 percent

- Introduction of tax credit benefit recipients

${ }^{a}$ Source: CPB (2002b). The effects on the government budget are in billion euro in 2006 (in 2002 prices), and do not account for the impact of behavioral changes on the government budget.

${ }^{b}$ The effect on the government budget of the introduction of the fifth bracket is not reported in CPB (2002b). 
Table G.2: Proposed changes by the Labor Party (PvdA) ${ }^{a}$

Effect on government budget

(in billion euro)

Labor taxes

- Change in health-care premiums households

$-0.50$

- Reduction in first tax bracket rate of -1.5 percentage points

$-2.25$

- Higher earned-income tax credit

$-0.60$

- Higher tax credit elderly

$-0.10$

- Higher child-care subsidies

$-0.10$

- Reduction in a number of work-related subsidies

$+0.35$

- Reduction in a number of deductibles

$+0.20$

Corporate taxes

- Reduction in unemployment insurance premiums for employers $\quad-0.40$

- Lower corporate income tax $\quad-1.00$

- Increase in taxes on profits of closely-held companies $\quad+0.10$

- Higher tax credit self-employed $\quad-0.50$

Consumption taxes

- Higher energy taxes $\quad+1.80$

$\begin{array}{lr}\text { - Tax on emissions by planes } & +0.25\end{array}$

- Abolishment of reduced tax rate on company cars $\quad+1.10$

$\begin{array}{lr}\text { - Tax on packaging } & +0.10\end{array}$

$\begin{array}{lr}\text { - Tax on surface-quarried minerals } & +0.10\end{array}$

Capital income taxes

- Higher mortgage interest rate deductability for new house owners $\quad-0.10$

- Reduction in deductability of pensions savings via annuities $\quad+0.30$

$\begin{array}{lr}\text { - Abolishment of general tax-favored savings } & +0.80\end{array}$

$\begin{array}{ll}\text { - Tax on land } & +0.15\end{array}$

${ }^{a}$ Source: CPB (2002b). The effects on the government budget are in billion euro in 2006 (in 2002 prices), and do not account for the impact of behavioral changes on the government budget. 
Table G.3: Proposed changes by the Christian-democratic party (CDA) ${ }^{a}$

Effect on government budget

(in billion euro)

Labor taxes

- Change in health-care premiums households $\quad+5.10$

- Income-dependent health care subsidy $\quad-2.40$

- Higher first and second tax bracket rate by 1.3 percentage points $\quad+2.55$

- Lower start of third tax bracket $\quad+0.40$

- Income-dependent child subsidies $\quad-3.30$

- Higher earned-income tax credit $\quad-1.00$

Corporate taxes

- Lower disability and unemployment insurance premiums employers $\quad-3.05$

- Abolishment of various employer subsidies $\quad+1.10$

Capital income taxes

- Abolishment of general tax credit for local taxes $\quad+0.30$

- More generous rent subsidies $\quad-0.90$

- Tax favored savings scheme $\quad-0.35$

- Reduction in deductability of pensions savings via annuities $\quad+0.30$

Benefits non-employed

- Higher refundable tax credit non-working partners

$-0.70$

${ }^{a}$ Source: CPB (2002b). The effects on the government budget are in billion euro in 2006 (in 2002 prices), and do not account for the impact of behavioral changes on the government budget. 
Table G.4: Proposed changes by the People's Party for Freedom and Democracy (VVD) ${ }^{a}$

Effect on government budget (in billion euro)

Labor taxes

- Abolishment of income-dependent health-care subsidies

$-5.00$

- Introduction of nominal health-care premiums

$+4.75$

- Reduction in first tax bracket rate by -0.4 percentage points

$-0.60$

- Reduction in fourth tax bracket rate by -3.0 percentage points

$-0.45$

- Higher earned-income tax credit

$-1.50$

- Higher tax credits elderly and children

$-0.20$

- Higher child-care subsidies

$-0.10$

- Reduction in a number of deductibles

$+0.55$

Corporate taxes

- Abolishment of employer subsidies for low-wage workers

$+0.90$

- Corporate income tax for pension funds

$+0.10$

Consumption taxes

- Higher energy taxes

Capital income taxes

- Reduction in deductability of pensions savings via annuities $\quad+0.30$

$\begin{array}{lr}\text { - Abolishment of general tax-favored savings } & +0.80\end{array}$

- Lower inheritance taxes $\quad-0.20$

- Abolishment of general tax credit for local taxes $\quad+0.30$

- Abolishment of local taxes on housing for private owners $\quad-1.10$

- Abolishment of local taxes on housing for firms $\quad-1.10$

- Abolishment of local user taxes on housing $\quad-0.90$

${ }^{a}$ Source: CPB (2002b). The effects on the government budget are in billion euro in 2006 (in 2002 prices), and do not account for the impact of behavioral changes on the government budget. 


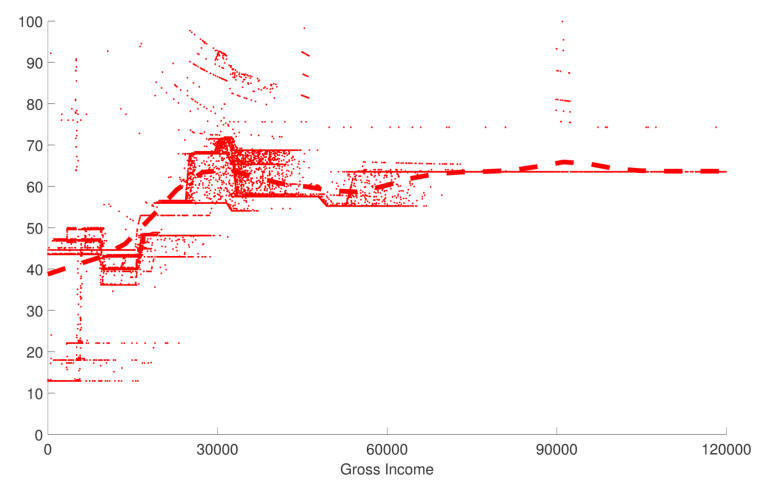

(a) Socialist Party (SP)

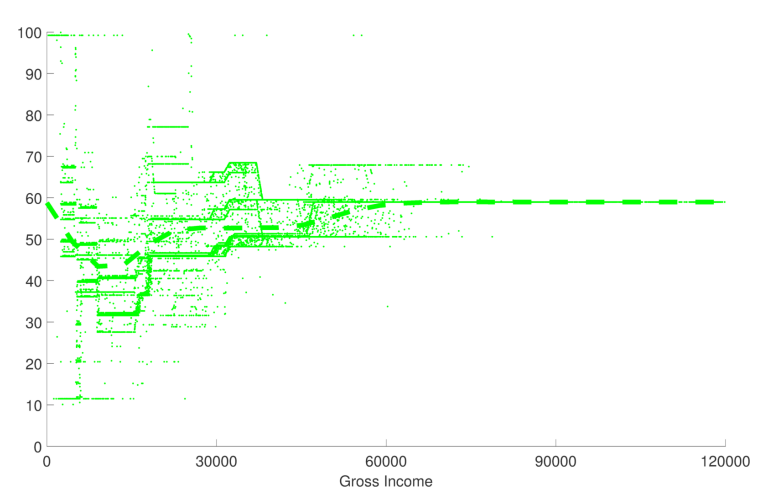

(c) Christian-Democratic Appeal (CDA)

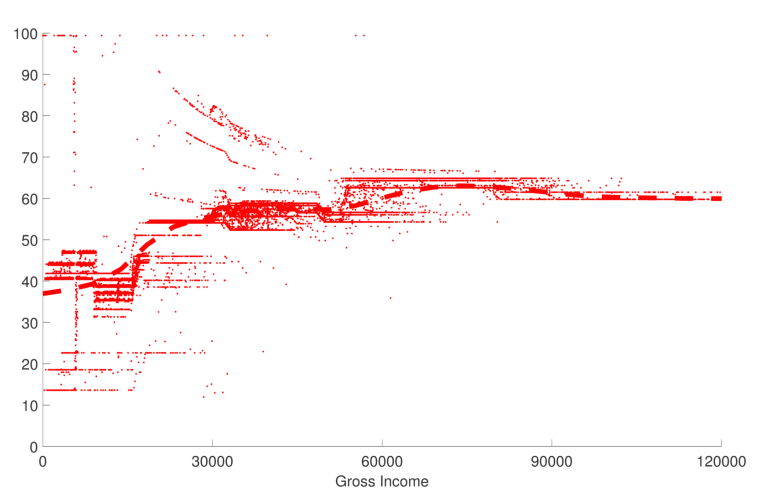

(b) Labor Party (PvdA)

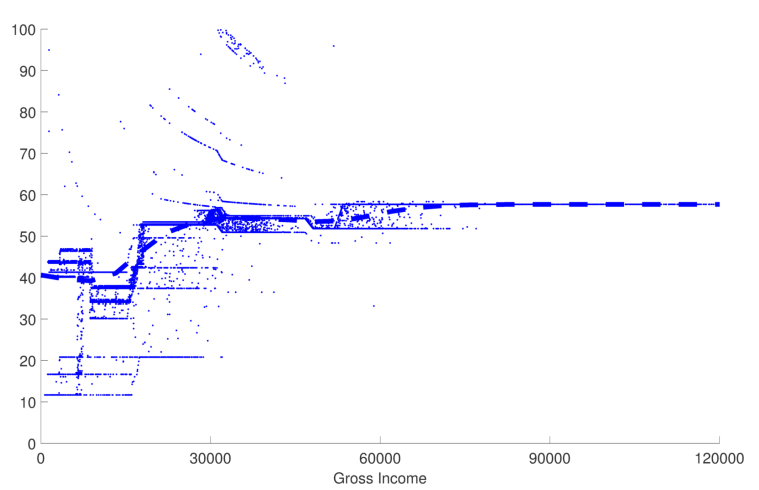

(d) People's Party for Freedom and Democr. (VVD)

Figure G.1: Scatter plots effective marginal tax rates by income of proposals political parties 


\section{H Decomposition social welfare weights political parties}

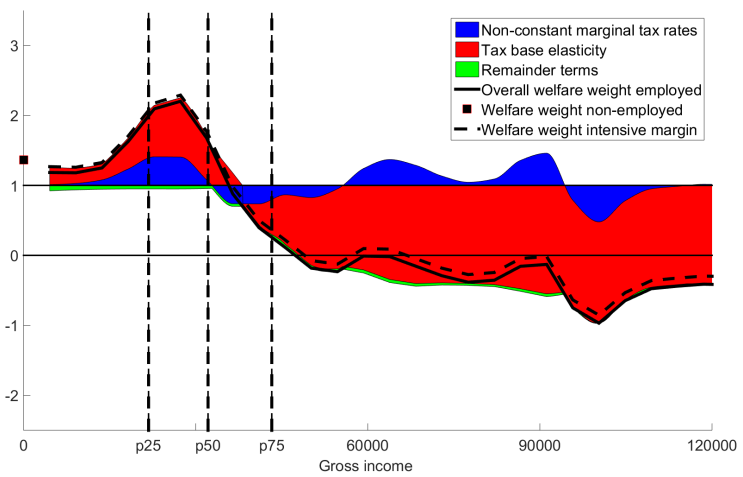

(a) Socialist Party (SP)

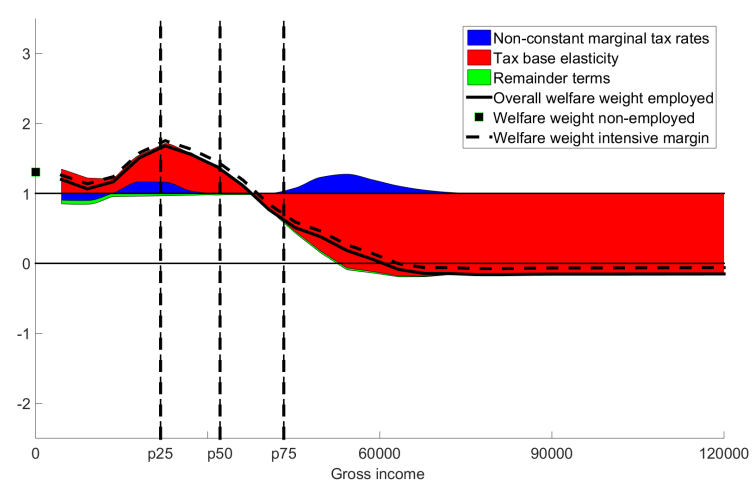

(c) Christian-Democratic Appeal (CDA)

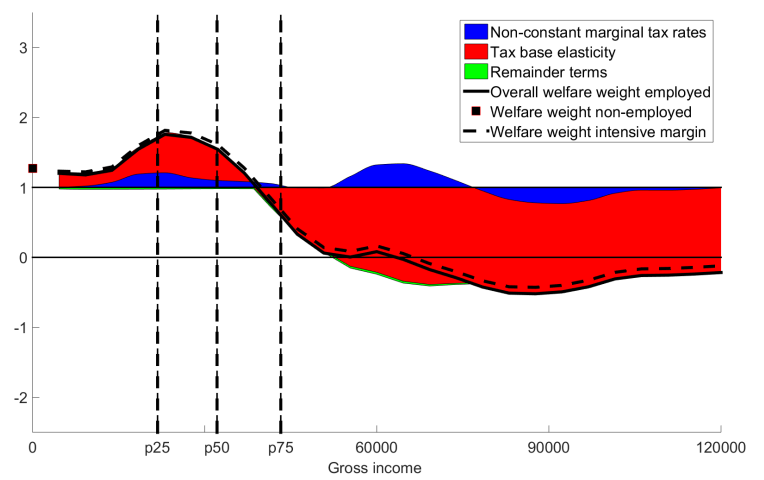

(b) Labor Party (PvdA)

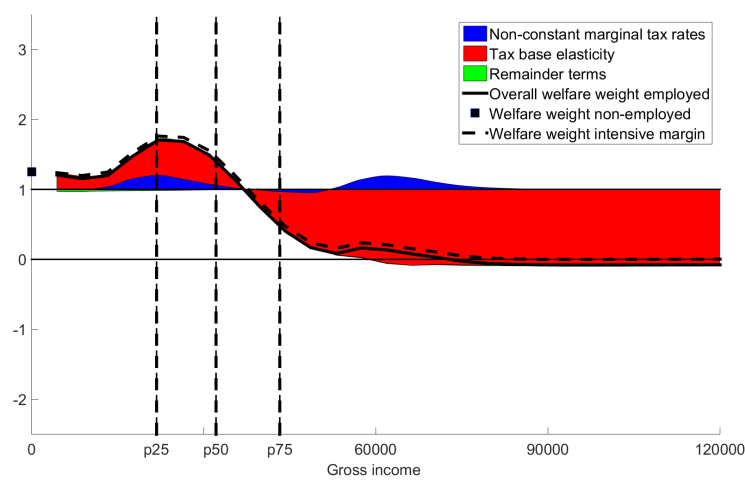

(d) People's Party for Freedom and Democr. (VVD)

Figure H.1: Decomposition social welfare weights of different political parties 